\title{
Bio-Inspired Protein-Based Nanoformulations for Cancer Theranostics
}

\author{
Yi Gou ${ }^{1}$, Dandan Miao' ${ }^{1}$, Min Zhou ${ }^{1}$, Lijuan Wang ${ }^{2}$, Hongyu Zhou ${ }^{2 *}$ and Gaoxing Su ${ }^{1 *}$ \\ 1 Jiangsu Province Key Laboratory of Inflammation and Molecular Drug Targets, School of Pharmacy, Nantong University, \\ Nantong, China, ${ }^{2}$ Guangzhou Key Laboratory of Environmental Exposure and Health and Guangdong Key Laboratory of \\ Environmental Pollution and Health, School of Environment, Jinan University, Guangzhou, China
}

Over the past decade, more interests have been aroused in engineering protein-based nanoformulations for cancer treatment. This excitement originates from the success of FDA approved Abraxane (Albumin-based paclitaxel nanoparticles) in 2005. The new generation of biocompatible endogenous protein-based nanoformulations is currently constructed through delivering cancer therapeutic and diagnostic agents simultaneously, as named potential theranostics. Protein nanoformulations are commonly incorporated with dyes, contrast agents, drug payloads or inorganic nanoclusters, serving as imaging-guided combinatorial cancer therapeutics. Employing the nature identity of proteins, the theranostics, escape the clearance by reticuloendothelial cells and have a long blood circulation time. The nanoscale sizet allows them to be penetrated deeply into tumor tissues. In addition, stimuli release and targeted molecules are incorporated to improve the delivery efficiency. The ongoing advancement of protein-based nanoformulations for cancer theranostics in recent 5 years is reviewed in this paper. Fine-designed nanoformulations based on albumin, ferritin, gelatin, and transferrin are highlighted from the literature. Finally, the current challenges are identified in translating protein-based nanoformulations from laboratory to clinical trials.

Keywords: protein nanoparticles, cancer therapeutics, theranostics, drug delivery, cancer diagnostics

\section{INTRODUCTION}

Cancer, a leading cause of death globally, reaching approximately 8.2 million mortalities yearly, poses an enormous burden on society (Torre et al., 2015; Mehra et al., 2017). Cancer counts as a multifactorial and refractory disease caused by the local tissue micro-environmental and genetic factors intertwined (Hanahan and Weinberg, 2011). Common treatment strategies, including radiotherapy and/or chemotherapy with surgery, result in high treatment failure rate (Aoun et al., 2015; Kouchakzadeh and Abbas Shojaosadati, 2016). The reasons of treatment failure are generally diverse: (1) cancer is commonly detected at a later stage, thus accuracy and susceptibility of diagnosis and monitoring methods for early-stage cancer require further improvement (Ge and Liu, 2013; Torre et al., 2015); (2) in most cases, the conventional chemotherapy have been disappointing in efficacy due to multidrug resistance (MDR) and severe side effects (Gelperina et al., 2005; Pérez-Tomás, 2006; Szakács et al., 2006; Ge and Liu, 2013); (3) the cancer therapeutic biological agents (inclusive of antibodies, proteins and nucleic acids), the new class of anticancer drugs, are commonly unstable in in vivo circulation, with rapid degradation and inactivation before 
reaching the target site (Panyam and Labhasetwar, 2003; Sinha and Trehan, 2003). Accordingly, early detection, effective diagnosis and effective treatment of cancer are needed to be optimized to increase the survival rate and decrease the cancer associated deaths.

"Theranostics," the portmanteau of therapeutics and diagnostics, has incorporated diagnostic and therapeutic functions into a single nanoplatform (Pene et al., 2009; Chen and Liu, 2016). It is noteworthy that the theranostics have been proposed as a new and revolutionary therapeutic concept in cancer therapy, enabling simultaneous diagnosis and treatment response monitoring using personalized medicine with high accuracy and specificity (Janib et al., 2010; Bardhan et al., 2011). Additionally, it is likely to incorporate numerous different therapeutic drugs into a single theranostics nanoplatform through judicious design to reach synergistic treatment of cancer (Moon et al., 2015; Chen and Liu, 2016). In this regard, theranostics have become a research orientation arousing great concern and been promising in the field of cancer treatment.

Considerable efforts have been recently made to develop new systems for cancer theranostics (Opoku-Damoah et al., 2016; Chen et al., 2017b; Guo et al., 2017; Mohammadi et al., 2017; Tekade and Sun, 2017; Yue et al., 2017). Thus, far, numerous types of theranostic platforms have been reported, consisting of protein nanocarriers (Ng et al., 2011; Chen and Liu, 2016; Truffi et al., 2016), liposome nanocarriers (Wang et al., 2014b; Dai and Yue, 2017), inorganic nanocarriers (Huang et al., 2011; Sharma et al., 2015), polymer nanocarriers (Kamaly et al., 2012; Charron et al., 2015; Sk and Kojima, 2015) and inorganic/organic hybrid nanocarriers (Barreto et al., 2011; Zhu et al., 2015; Li et al., 2017). Among these platforms, protein-based nanoplatforms have aroused the greatest concern by virtue of their biodegradability, biocompatibility, no or low toxicity and ease of modification (Maham et al., 2009; Elzoghby, 2013; Yewale et al., 2013; Chen and Liu, 2016; Kouchakzadeh and Abbas Shojaosadati, 2016). Some proteins, e.g., transferrin and lactoferrin, can be specifically bound to receptor(s) highly expressed in considerable cancer cells via receptor-ligand interaction, enabling the construction of active targeted theranostic nanoplatforms (Kanwar et al., 2016; Wang et al., 2016a, 2017a). Furthermore, in the presence of reactive groups such as $-\mathrm{COOH},-\mathrm{NH}_{2}$, and $-\mathrm{OH}$, protein-based theranostic platforms can be further decorated with functional molecules for different purposes. Numerous proteins as versatile platforms for delivering therapeutic agents have been elucidated in previous review articles (Yewale et al., 2013; Paliwal and Palakurthi, 2014; Kouchakzadeh and Abbas Shojaosadati, 2016).

This review article stresses the protein-based multifunctional theranostics progress in the past 5 years (Table 1) and summaries critical foundation for further studying theranostics. The therapeutic methods include photothermal therapy (PTT), photodynamic therapy (PDT) and chemotherapy. The diagnostic or imaging methods included magnetic resonance (MR) imaging, fluorescence imaging, computed tomography (CT) imaging, photoacoustic (PA) imaging, positron emission tomography (PET) imaging and so on. The combinatorial strategies between diagnostic and therapeutic methods are summarized in Figure 1. Properties of commonly used proteins, i.e., albumin, ferritin, gelatin, and transferrin, were introduced. The preparation methods and key outcomes of in vitro or in vivo studies of these protein-based nanoformulations for cancer theranostics were elaborated.

\section{ALBUMIN-BASED NANOFORMULATIONS}

\section{Albumin and Its Properties}

Albumins are obtained commercially in considerable amount from human serum (human serum albumin, HSA), bovine serum (bovine serum albumin, BSA), rat serum (RSA) and egg white (ovalbumin) (Karimi et al., 2016). Based on practicality, this review focus on HSA and BSA.

BSA shares ca. 76\% sequence homology with HSA (Anand and Mukherjee, 2013), and is very soluble with a $69,323 \mathrm{Da}$ molecular weight, consisting of 583 amino acid residues. BSA has an isoelectric point ( $\mathrm{pI}$ ) of 4.7 with a net charge of $-18 \mathrm{mV}$ (Anand and Mukherjee, 2013). BSA molecule is heart-shaped, consisting of three repeating domains (labeled I-III), with each of which falling into two sub-domains A and B (Majorek et al., 2012). BSA is extensively adopted for cancer theranostics by virtue of low cost, abundance, ease of purification and proper delivering properties.

HSA, the most abundant plasma protein $(35-50 \mathrm{mg} / \mathrm{mL}$ human serum), is synthesized in the liver. HSA is a singlechain and non-glycosylated polypeptide with $66,500 \mathrm{Da}$ in molecular weight, consisting of 585 amino acid residues, and heart-shaped with $80 \times 80 \times 30 \AA$ in ca. dimensions (Sugio et al., 1999). From X-ray crystallographic analyses, the vital difference between BSA and HSA is that the former contains two tryptophan amino acid residues (Trp-135 and Trp-212), whereas the latter has merely one, Trp-214. HSA is very soluble, being extremely robust toward temperature (available at $60^{\circ} \mathrm{C}$ for $10 \mathrm{~h}$ ), $\mathrm{pH}$ (stable in $\mathrm{pH} 4-9$ ) and organic solvents. Besides, HSA protein has preferentially been uptaken to tumor interstitium via the pathway of SPARC glycoprotein and gp60 glycoprotein transcytosis. These properties as well as its deficient toxicity, immunogenicity, and biodegradability make it an ideal candidate for cancer theranostics.

\section{HSA for Cancer Theranostics}

HSA has broadly served as a natural carrier to isolate organic molecules or inorganic oxide, inclusive of IR780, superparamagnetic iron oxide, IR825, and chlorin e6 (Ce6), for synthesizing effective theranostic agents.

\section{Individual HSA-Dye Complexes}

HSA is well-known with multiple hydrophobic binding pockets, and able to be bound non-covalently with many organic dyes, forming HSA-dye complexes with a high fluorescence quantum yield. In recent years, near-infrared (NIR) dyes, e.g., IR780, indocyanine green (ICG) and IR825, are broadly employed for cancer theranostics because of their relatively deep penetration and low interference. IR825 can be bound to the hydrophobic domain of HSA (the molar ratio of $1: 1$ ) via hydrophobic interactions, which fabricates a HSA-IR825 complex (Figure 2A) (Chen et al., 2014c). The HSA-IR825 complex have a high 
TABLE 1 | Overview of the protein-based nanoformulations for cancer theranostics.

\begin{tabular}{|c|c|c|c|c|}
\hline Protein & Formulation & Application & Key outcomes of in vitro/in vivo study & References \\
\hline HSA & HSA-ICG NPS & $\begin{array}{l}\text { Fluorescence and PA } \\
\text { dual-modal imaging-guided } \\
\text { phototherapy }\end{array}$ & $\begin{array}{l}\text { In } 4 \mathrm{~T} 1 \text { tumor-bearing mice, the normal, tumor and its margin } \\
\text { tissue can be clearly identified via fluorescence and PA imaging. } \\
\text { After i.v. injection of the NPs followed by imaging-guided precision } \\
\text { PDT/PTT, the } 4 \mathrm{~T} 1 \text { tumor was completely eradicated, no } \\
\text { treatments-induced toxicity and tumor recurrence were observed. }\end{array}$ & Sheng et al., 2014 \\
\hline HSA & HSA-IR825 complex & Imaging-guided PTT & $\begin{array}{l}\text { The } 4 \mathrm{~T} 1 \text { tumor could be clearly identified from } 1 \text { to } 12 \mathrm{~h} \text { post } \\
\text { injection. After i.v. injection of the complex followed by } 808 \mathrm{~nm} \\
\text { laser irradiation, the } 4 \mathrm{~T} 1 \text { tumor was significant eradicated and no } \\
\text { appreciable toxic side was observed. }\end{array}$ & Chen et al., 2014c \\
\hline HSA & $\begin{array}{l}\text { HSA-Gd-IR825 } \\
\text { nanocomplex }\end{array}$ & $\begin{array}{l}\text { Fluorescence and MR } \\
\text { dual-modal imaging-guided } \\
\text { PTT }\end{array}$ & $\begin{array}{l}\text { The nanocomplex can be used for effective mapping of the } \\
\text { sentinel lymph node nearby tumors, and the mapping signal is } \\
\text { clearest at } \sim 30 \text { min post injection. Photothermal ablation of the } \\
\text { HSA-Gd-IR825 combined with surgical removal of primary tumors } \\
\text { provides significant therapeutic advances in preventing } 4 T 1 \text { tumor } \\
\text { metastasis and prolonging animal survival. }\end{array}$ & Chen et al., 2014a \\
\hline HSA & HSA-Ce6-PTX-RGD & $\begin{array}{l}\text { MR and fluorescence- } \\
\text { imaging-guided } \\
\text { chemotherapy and PDT }\end{array}$ & $\begin{array}{l}\text { Upon i.v. injection into U87MG tumor-bearing mice, the nano-drug } \\
\text { could be effectively tracked by dual modal imaging and shown } \\
\text { excellent tumor growth inhibition effect. }\end{array}$ & Chen et al., 2015b \\
\hline HSA & $\begin{array}{l}\text { Cy5/Qsy21 labeled- } \\
\text { Pt(IV)-probe@HSA }\end{array}$ & $\begin{array}{l}\text { Imaging-guided } \\
\text { chemotherapy }\end{array}$ & $\begin{array}{l}\text { Upon UV light irradiation, Pt(IV)-probe@HSA showed enhanced } \\
\text { cell death and cell apoptosis at both cisplatin-resistant A2780cis } \\
\text { and sensitive A2780 cell lines. }\end{array}$ & Li et al., 2015 \\
\hline HSA & Melanin/PTX-HSA NPs & $\begin{array}{l}\text { PA-imaging-guided } \\
\text { chemotherapy }\end{array}$ & $\begin{array}{l}\text { In vitro, the NPs showed enhanced PA signal and cytotoxicity } \\
\text { against MDA-MB- } 231 \text { cancer cells. In vivo, the NPs efficiently } \\
\text { accumulated inside the MDA-MB- } 231 \text { tumor, resulting in inhibiting } \\
\text { tumor growth effectively and visualizing tumors photoacoustically. }\end{array}$ & Sim et al., 2015 \\
\hline HSA & $\begin{array}{l}\text { Porphyrin-MB-PTX-HSA } \\
\text { NPs }\end{array}$ & $\begin{array}{l}\text { PA and } \\
\text { ultrasound-imaging-guided } \\
\text { chemotherapy }\end{array}$ & $\begin{array}{l}\text { The MDA-MB-231 tumor and neo-vessels in the tumor region } \\
\text { could be clearly visualized after } 3 \text { min post injection. Exposure to } \\
\text { the focused ultrasound triggered the collapse of the } \\
\text { Porphyrin-MB-PTX-HSA NPs, resulting in the PTX-HSA-NPs } \\
\text { suppressed MDA-MB- } 231 \text { tumor growth 10-fold higher than } \\
\text { without exposure to ultrasound. }\end{array}$ & Moon et al., 2015 \\
\hline HSA & HSA-Ce6 nanoassemblies & $\begin{array}{l}\text { Fluorescence/PA/MR } \\
\text { triple-modal imaging-guided } \\
\text { PDT }\end{array}$ & $\begin{array}{l}\text { The nanoassemblies could be used for PA, MRI and fluorescence } \\
\text { triple-modal tumor imaging imaging in } 4 \mathrm{~T} 1 \text { tumor-bearing mice via } \\
\text { i.v. injection. After i.v. injection of the nanoassemblies followed by } \\
\text { low-energy NIR irradiation, the } 4 \mathrm{~T} 1 \text { tumor was completely } \\
\text { suppressed without therapy-induced side effects and tumor } \\
\text { recurrence. }\end{array}$ & Hu et al., 2016 \\
\hline HSA & HSA-FePc NPs & PA imaging-guided PTT & $\begin{array}{l}\text { The NPs are excellent PA imaging agent, which can clearly show a } \\
\text { clear } 4 \mathrm{~T} 1 \text { tumor microstructure with higher spatial and contrast } \\
\text { resolution compared with FePc alone molecules. After i.v. } \\
\text { injection, the NPs exhibited efficient cancer therapy, no obviously } \\
\text { weight loss and low long-term toxicity were observed. }\end{array}$ & Jia et al., 2017 \\
\hline HSA & PFT-Hcy-HSA-Cy7-pTFT & $\begin{array}{l}\text { Optical and }{ }^{19} \mathrm{~F} \mathrm{MR} \\
\text { imaging-guided } \\
\text { chemotherapy }\end{array}$ & $\begin{array}{l}\text { The }{ }^{19} \text { F signals of PFT-Hcy-HSA-Cy7-pTFT are clearly visible in } \\
\text { tumor-bearing mouse. The inhibitory tumor (A549) growth effect of } \\
\text { PFT-Hcy-HSA-Cy7-pTFT was found to be } 0.8 \text {-fold more than that } \\
\text { of the pTFT alone. }\end{array}$ & Lisitskiy et al., 2017 \\
\hline HSA & $\begin{array}{l}\text { HSA-gemcitabine/IR780 } \\
\text { complex }\end{array}$ & $\begin{array}{l}\text { NIR imaging-guided } \\
\text { chemotherapy }\end{array}$ & $\begin{array}{l}\text { Compared to IR780 alone, the complex showed enhanced } \\
\text { accumulation and long-term retention in BxPC- } 3 \text { pancreatic tumor } \\
\text { tissues, resulting in inhibiting tumor growth effectively with minimal } \\
\text { side effects. }\end{array}$ & Han et al., 2017 \\
\hline
\end{tabular}


TABLE 1 | Continued

\begin{tabular}{|c|c|c|c|c|}
\hline Protein & Formulation & Application & Key outcomes of in vitro/in vivo study & References \\
\hline HSA & $\begin{array}{l}\text { HSA-coated } \\
\text { superparamagnetic iron } \\
\text { oxide NPs }\end{array}$ & $\begin{array}{l}\text { MRI and thermoacoustic } \\
\text { imaging-guided } \\
\text { thermoacoustic therapy }\end{array}$ & $\begin{array}{l}\text { Based on MRI and TA imaging, the NPs provide comprehensive } \\
\text { and complementary information for } 4 \mathrm{~T} 1 \text { tumors. Meanwhile, the } \\
\text { NPs mediated TA therapy exhibits excellent anti-tumor efficacy for } \\
\text { deep tumor models. }\end{array}$ & Wen et al., 2017 \\
\hline BSA & $\begin{array}{l}\text { BSA functionalized } \\
\text { Nano-rGO }\end{array}$ & $\begin{array}{l}\text { PA/ultrasonic dual-modality } \\
\text { imaging-guided PTT }\end{array}$ & $\begin{array}{l}\text { The theranostic agent not only showed rapid and significant PA } \\
\text { signal enhancement in the MCF-7 tumor area, but also can } \\
\text { effectively kill tumor cells in vivo with no noticeable organs toxic. }\end{array}$ & Sheng et al., 2013 \\
\hline BSA & squaraine@BSA & $\begin{array}{l}\text { Dual-functional NIR probe } \\
\text { for targeted optical imaging } \\
\text { and selective PTT of cancer. }\end{array}$ & $\begin{array}{l}\text { The optimal imaging and PTT window for KB xenografted tumor } \\
\text { was within } 6 \mathrm{~h} \text { post-injection. After a tail veins injection of the } \\
\text { theranostic agent followed by } 680 \mathrm{~nm} \text { laser irradiation, the KB } \\
\text { xenografted tumor was significantly suppressed. }\end{array}$ & Gao et al., 2014 \\
\hline BSA & UCNP@BSA-RB\&IR825 & $\begin{array}{l}\text { Imaging-guided combined } \\
\text { photothermal and } \\
\text { photodynamic therapy }\end{array}$ & $\begin{array}{l}\text { The theranostic agent irradiated with dual lasers at } 808 \mathrm{~nm} \text { and } \\
980 \mathrm{~nm} \text { show stronger anti-cancer effect than that at individual } \\
\text { wavelength both in vitro and in vivo. }\end{array}$ & Chen et al., 2014b \\
\hline BSA & $\mathrm{Fe}_{3} \mathrm{O}_{4}-\mathrm{BSA} @ \mathrm{DOX}-\mathrm{PEG}$ & $\begin{array}{l}\text { Combined MRI diagnostics } \\
\text { and chemotherapy }\end{array}$ & $\begin{array}{l}\text { The theranostic agent showed superparamagnetic property and } \\
\text { high } T_{2} \text {-relaxivity value, and displayed similar cytotoxicity against } \\
\text { HEK } 293 \text { and C6 cells as the DOX alone. }\end{array}$ & $\begin{array}{l}\text { Semkina et al., } \\
2015\end{array}$ \\
\hline BSA & $\begin{array}{l}\text { Gemcitabine-loaded } \\
\text { magnetic BSA nanospheres } \\
\text { modified with cetuximab }\end{array}$ & $\begin{array}{l}\text { Simultaneous targeting, MRI } \\
\text { diagnostics, and } \\
\text { double-targeted } \\
\text { thermochemotherapy of } \\
\text { pancreatic cancer cells }\end{array}$ & $\begin{array}{l}\text { The theranostic agent not only can effectively distinguish different } \\
\text { EGFR-expressing pancreatic cancer cells, but also can evaluate } \\
\text { non-invasive methods for different targeting effects by MRI. } \\
\text { Combined antibodies and magnetic targeting, the theranostic } \\
\text { agent can efficiently inhibit or kill AsPC-1 cells. }\end{array}$ & Wang et al., 2015 \\
\hline BSA & $\mathrm{Fe}_{5} \mathrm{C}_{2}-\mathrm{BSA}-\mathrm{DOX} \mathrm{NPs}$ & $\begin{array}{l}\text { Multi-stimuli-regulated } \\
\text { photo-chemothermal } \\
\text { cancer therapy }\end{array}$ & $\begin{array}{l}\text { The NPs could be used for MRI and fluorescence tumor imaging in } \\
\text { SK-OV-3 tumor-bearing mice via i.v. injection. Under the } \\
\text { synergistic effect of magnetic targeting, PTT and the increased } \\
\text { drug release, the NPs have no systemic toxicity and show good } \\
\text { SK-OV-3 tumor elimination. }\end{array}$ & Yu et al., 2016 \\
\hline BSA & Gd:CuS@BSA NPs & $\begin{array}{l}\text { PA/MR bimodal } \\
\text { imaging-guided } \\
\text { tumor-targeted PTT }\end{array}$ & $\begin{array}{l}\text { The NPs have significant SK-OV-3 tumor-targeted PA/MR imaging } \\
\text { performance, as well as effective SK-OV-3 tumor ablation. }\end{array}$ & Yang et al., 2016 \\
\hline BSA & $\begin{array}{l}\text { PEG-BSA-imidazole } \\
\text { modified with either Cy5.5 } \\
\text { or BHQ-3 }\end{array}$ & $\begin{array}{l}\mathrm{pH} \text {-activatable on/off tumor } \\
\text { targeting probe for the } \\
\text { theranostic }\end{array}$ & $\begin{array}{l}\text { The theranostic agent displayed significant cytotoxicity for MCF-7 } \\
\text { and A549 cells, and showed a strong fluorescence signal in the } \\
\text { endosomal region of MCF-7 cells. }\end{array}$ & Lee et al., 2016 \\
\hline BSA & $\begin{array}{l}\text { [FITC]-BSA-Gd/1,3-bis }(2- \\
\text { chloroethyl)-1-nitrosourea } \\
\text { NPs }\end{array}$ & $\begin{array}{l}\text { MR and fluorescence } \\
\text { imaging-guided } \\
\text { chemotherapy }\end{array}$ & $\begin{array}{l}\text { The NPs enable dual imaging for real-time tracking of } \\
\text { chemotherapeutic agent in vitro and in vivo, and can also } \\
\text { effectively inhibit MBR } 261-2 \text { tumor growth. }\end{array}$ & Wei et al., 2016 \\
\hline BSA & $\begin{array}{l}\text { Folate(FA)-BSA-c-PheoA } \\
\text { conjugate:GO complex } \\
\text { incorporated free PheoA }\end{array}$ & $\begin{array}{l}\text { Active-targeted and } \\
\text { pH-responsive theranostic } \\
\text { agent for fluorescence } \\
\text { imaging-guided PTT and } \\
\text { PDT }\end{array}$ & $\begin{array}{l}\text { The theranostic agent showed the strongest fluorescence signal at } \\
\text { the MCF7 tumor at } 3 \mathrm{~h} \text { post-injection. After i.v. injection of the } \\
\text { theranostic agent followed by } 671 \mathrm{~nm} \text { laser irradiation, the B16F10 } \\
\text { tumor was suppressed, and no acute toxicity was observed. }\end{array}$ & $\begin{array}{l}\text { Battogtokh and Ko, } \\
2016\end{array}$ \\
\hline BSA & Prussian blue-BSA-ICG NPs & $\begin{array}{l}\text { MR and NIR fluorescence } \\
\text { bimodal imaging guided } \\
\text { laser mediated } \\
\text { combinatorial phototherapy }\end{array}$ & $\begin{array}{l}\text { After i.v. injection of the NPs, time dependent NIR fluorescence } \\
\text { signal and MRI signal was increase at the SCC7 tumor site. Upon } \\
\text { irradiation of } 808 \mathrm{~nm} \text { laser irradiation, the SCC7 tumor growth was } \\
\text { efficiently suppressed without tumor recurrence. }\end{array}$ & Sahu et al., 2016 \\
\hline BSA & $\begin{array}{l}\text { DOX-loaded } \\
\text { UCN/ZnPc@FA-BSA-PCL }\end{array}$ & $\begin{array}{l}\text { Simultaneous tumor cell } \\
\text { imaging, PDT and } \\
\text { chemotherapy }\end{array}$ & $\begin{array}{l}\text { After } 4 \mathrm{~h} \text { of incubation, DOX and UCN fluorescent signals can be } \\
\text { clearly detected in HeLa cells. Compared with single PDT or DOX } \\
\text { chemotherapy groups, the theranostic agent showed significantly } \\
\text { enhanced HeLa cell killing efficiency. }\end{array}$ & Dong et al., 2016 \\
\hline BSA & $\begin{array}{l}\mathrm{BSA}-\mathrm{MnO}_{2}-\mathrm{ICG} \text { NPs and } \\
\mathrm{BSA}-\mathrm{MnO}_{2}-\mathrm{PTX} \mathrm{NPS}\end{array}$ & $\begin{array}{l}\text { MR imaging-guided PTT } \\
\text { and MR imaging-guided } \\
\text { chemotherapy }\end{array}$ & $\begin{array}{l}\text { Both NPs showed admirable renal and tumor imaging ability as } \\
\text { well as significant } 4 \mathrm{~T} 1 \text { tumor inhibition via i.v. injection. }\end{array}$ & Pan et al., 2017 \\
\hline BSA & $\mathrm{MoS}_{2}-\mathrm{Gd}-\mathrm{BSA}$ & $\begin{array}{l}\text { Dual-modality MR and PA } \\
\text { imaging-guided PTT }\end{array}$ & $\begin{array}{l}\text { The enhanced MR/PA signals were detected in the } 4 \mathrm{~T} 1 \text { tumor site } \\
\text { post-injection of the theranostic agent. After i.v. injection of the } \\
\text { theranostic agent followed by } 808 \mathrm{~nm} \text { laser irradiation, the } 4 \mathrm{~T} 1 \\
\text { tumor was suppressed, and the negligible toxicity was observed. }\end{array}$ & Chen et al., 2017a \\
\hline BSA & $\mathrm{Mn}_{3} \mathrm{O}_{4}$-BSA-EDTA & $\begin{array}{l}\text { Multifunctional } \\
\text { imaging-guided PTT }\end{array}$ & $\begin{array}{l}\text { The theranostic agent exhibited applicability a } T_{1}-T_{2} \text { dual-model } \\
\text { MR imaging and strong NIR ( } 700-1000 \mathrm{~nm}) \text { imaging in vitro and } \\
\text { in vivo. After i.v. injection of the theranostic agent followed by } \\
785 \mathrm{~nm} \text { laser irradiation, the HCT116 tumor was suppressed, and } \\
\text { the low toxicity was observed. }\end{array}$ & Liu et al., 2017 \\
\hline
\end{tabular}


TABLE 1 | Continued

\begin{tabular}{|c|c|c|c|c|}
\hline Protein & Formulation & Application & Key outcomes of in vitro/in vivo study & References \\
\hline BSA & $\begin{array}{l}\mathrm{Gd}_{2} \mathrm{O}_{3} @ \mathrm{BSA} \text { conjugating } \\
\text { Chlorin e6 }\end{array}$ & $\begin{array}{l}\text { MR imaging-guided } \\
\text { photo-induced therapy }\end{array}$ & $\begin{array}{l}\text { The theranostic agent can be used for tumor localization and } \\
\text { visualization the in vivo distribution of Chlorin e6. After i.v. injection } \\
\text { of the theranostic agent followed by } 660 \mathrm{~nm} \text { laser irradiation, the } \\
\text { 4T1 tumor was suppressed, and no influence on the normal } \\
\text { tissues was observed. }\end{array}$ & Zhou et al., 2017 \\
\hline Ferritin & $\begin{array}{l}\text { ZW800-labeled } \\
\text { ZnF }_{16} \text { Pc-ferritin- RGD4C }\end{array}$ & $\begin{array}{l}\text { Fluorescence } \\
\text { imaging-guided PDT }\end{array}$ & $\begin{array}{l}\text { The theranostic agent showed admirable liver and U87MG tumor } \\
\text { imaging ability, significant U87MG tumor inhibition as well as } \\
\text { minimal toxicity to normal tissues via i.v. injection. }\end{array}$ & Zhen et al., 2013b \\
\hline Ferritin & $\begin{array}{l}\text { ZW800-labeled } \\
\text { DOX-ferritin- RGD4C }\end{array}$ & $\begin{array}{l}\text { Fluorescence } \\
\text { imaging-guided } \\
\text { chemotherapy }\end{array}$ & $\begin{array}{l}\text { After injection of the theranostic agent, the fluorescence signals in } \\
\text { the tumor were the strongest and two-fold higher than those in the } \\
\text { liver. The theranostic agent showed a longer circulation half-life, } \\
\text { significant U87MG tumor inhibition as well low cardiotoxicityl via } \\
\text { i.v. injection. }\end{array}$ & Zhen et al., 2013a \\
\hline Ferritin & $\begin{array}{l}\text { Gd-HPDO3A-apoferritin- } \\
\text { curcumin }\end{array}$ & $\begin{array}{l}\text { MR imaging-guided } \\
\text { targeting chemotherapy }\end{array}$ & $\begin{array}{l}\text { The theranostic agent induced MR contrast is stronger in MCF-7 } \\
\text { cells than in MDA-MB-231cells. The theranostic agent have a } \\
\text { significant reduction of MCF- } 7 \text { cell proliferation at a concentration } \\
\text { of } 97 \mu \mathrm{g} / \mathrm{ml} \text {. }\end{array}$ & $\begin{array}{l}\text { Geninatti Crich } \\
\text { et al., } 2015\end{array}$ \\
\hline Ferritin & $\begin{array}{l}\text { Gd-HPDO3A-L-ferritin- } \\
\text { curcumin }\end{array}$ & $\begin{array}{l}\text { MR imaging-guided } \\
\text { targeting chemotherapy }\end{array}$ & $\begin{array}{l}\text { Although the theranostic agent showed relatively low MRI } \\
\text { sensitivity, it can effectively destroy the viability and self-renewal of } \\
\text { MDA-MB- } 231 \text { and TUBO cells spheres in vitro, and to induce the } \\
\text { regression of TUBO tumor in mice. }\end{array}$ & Conti et al., 2016 \\
\hline Gelatin & $\begin{array}{l}\mathrm{Fe}_{3} \mathrm{O}_{4} @ \text { gelatin conjugating } \\
\text { FITC and Pt(IV) prodrug }\end{array}$ & $\begin{array}{l}\text { Enzyme-stimulated } \\
\text { theranostics agent for } \\
\text { chemotherapy, MR imaging } \\
\text { and fluorescence sensor }\end{array}$ & $\begin{array}{l}\text { The } I C_{50} \text { value of the theranostic agent is much lower than free } \\
\mathrm{Pt}(\mathrm{I}) \text { prodrug. Significant enhancement in MR signals was } \\
\text { observed at the tumor site after in situ injection of the theranostic } \\
\text { agent. }\end{array}$ & Cheng et al., 2014 \\
\hline Gelatin & $\begin{array}{l}\text { Angio-DOX-dendrigraft } \\
\text { poly-lysine-gelatin }\end{array}$ & $\begin{array}{l}\text { Simultaneous } \\
\text { cancer-targeted fluorescent } \\
\text { imaging and chemotherapy }\end{array}$ & $\begin{array}{l}\text { The theranostic agent showed good targeting efficiency, well } \\
\text { penetration ability as well as significantly inhibited } 4 \mathrm{~T} 1 \text { tumor } \\
\text { growth. }\end{array}$ & Hu et al., 2015 \\
\hline Gelatin & DOX-AuNPs@gelatin & $\begin{array}{l}\text { Chemotherapy and } \\
\text { intracellular imaging }\end{array}$ & $\begin{array}{l}\text { DOX-based fluorescence allows real-time monitoring of drug } \\
\text { uptake, release and distribution in MCF-7 cells. Free DOX is more } \\
\text { toxic to MCF-7 cells than DOX-AuNPs@gelatin. }\end{array}$ & $\begin{array}{l}\text { Suarasan et al., } \\
2016\end{array}$ \\
\hline Gelatin & DOX-gelatin-EGCG AuNPs & $\begin{array}{l}\text { Enzyme-responsive } \\
\text { theranostics agent for } \\
\text { real-time monitoring and } \\
\text { chemotherapy }\end{array}$ & $\begin{array}{l}\text { The theranostic agent could be effectively tracked by monitoring } \\
\text { the recovery of the DOX fluorescence signal and shown } \\
\text { significantly inhibit the growth of PC-3 cells. }\end{array}$ & Tsai et al., 2016 \\
\hline Gelatin & $\begin{array}{l}\text { Paclitaxel-loaded gelatin } \\
\text { oleic acid } \\
\text { superparamagnetic NPS }\end{array}$ & $\begin{array}{l}\text { MR imaging-guided } \\
\text { chemotherapy }\end{array}$ & $\begin{array}{l}\text { The NPs can be used as } T_{2} \text {-weighted MRI contrast agents in } \\
\text { cancer cells. After the tail vein injection, the NPs have longer } \\
\text { systemic circulation time and better anticancer activity than } \\
\text { Taxol }{ }^{\circledR} \text {. }\end{array}$ & Tran et al., 2017a,b \\
\hline
\end{tabular}


TABLE 1 | Continued

\begin{tabular}{|c|c|c|c|c|}
\hline Protein & Formulation & Application & Key outcomes of in vitro/in vivo study & References \\
\hline Transferrin & $\begin{array}{l}\text { DOX-Graphene- } \mathrm{SiO}_{2}^{-} \\
\text {coated quantum dots-Tf } \\
\text { conjugates }\end{array}$ & $\begin{array}{l}\text { Simultaneous } \\
\text { cancer-targeted fluorescent } \\
\text { imaging, monitoring and } \\
\text { chemotherapy }\end{array}$ & $\begin{array}{l}\text { DOX-based fluorescence allows real-time monitoring of drug } \\
\text { release and distribution in HeLa cells. However, the conjugates } \\
\text { showed lower toxicity effect than DOX alone on HeLa and } \\
\text { HEK293 cell lines. }\end{array}$ & Chen et al., 2013 \\
\hline Transferrin & $\begin{array}{l}\text { PEGylated fluorescent } \\
\text { nanodiamond-Tf-DOX }\end{array}$ & $\begin{array}{l}\text { Simultaneous } \\
\text { cancer-targeted fluorescent } \\
\text { imaging and chemotherapy }\end{array}$ & $\begin{array}{l}\text { It can discriminate L-02 normal cells form HepG2 tumor cells in } \\
\text { terms of fluorescence intensity and cytotoxicity. }\end{array}$ & Wang et al., 2014a \\
\hline Transferrin & $\begin{array}{l}\text { Docetaxel- and ultra bright } \\
\text { gold clusters-loaded } \\
\text { Tf-TPGS }\end{array}$ & $\begin{array}{l}\text { Simultaneous } \\
\text { cancer-targeted imaging } \\
\text { and chemotherapy }\end{array}$ & $\begin{array}{l}\text { The theranostic agent showed } 71.73 \text { times more potency than } \\
\text { Taxotere } ® \text { after } 24 \mathrm{~h} \text { treatment with MDA-MB-231-luc breast } \\
\text { cancer cells. } 24 \mathrm{~h} \text { after the } 4 \text { th injection on } 24 \text { th day the } \\
\text { fluorescence intensity was not significantly decreased in the tumor, } \\
\text { liver and bladder. After i.v. injection of the theranostic agent, the } \\
\text { MDA-MB-231-luc tumor was suppressed, and no significant body } \\
\text { weight loss was observed. }\end{array}$ & Muthu et al., 2015 \\
\hline Transferrin & $\begin{array}{l}\text { Paclitaxel-loaded } \\
\mathrm{Tf}_{-} \mathrm{Fe}_{3} \mathrm{O}_{4} / \text { mesoporous silica } \\
\text { (core/shell)-Cy7 NPs }\end{array}$ & $\begin{array}{l}\text { Simultaneous } \\
\text { cancer-targeted NIR } \\
\text { fluorescence/MR imaging } \\
\text { and chemotherapy }\end{array}$ & $\begin{array}{l}1 \text { to } 24 \mathrm{~h} \text { after injection, the tumor can be clearly visualized. The } \\
\text { NPs showed higher anti-cancer activity on HeLa cells than free } \\
\text { PTX. }\end{array}$ & Jiao et al., 2015 \\
\hline Transferrin & Cy5.5-loaded N-NE3TA-Tf & $\begin{array}{l}\text { Targeted iron chelation } \\
\text { cancer therapy and NIR } \\
\text { fluorescence imaging }\end{array}$ & $\begin{array}{l}\text { The theranostic agent displayed significant inhibitory activity } \\
\text { against HeLa, HT29 and PC3 cells, and the NIR fluorescence } \\
\text { signals of the theranostic agent can be clearly detected in HeLa, } \\
\text { HT29, and PC3 cells. }\end{array}$ & Kang et al., 2016 \\
\hline Transferrin & $\begin{array}{l}\text { Docetaxel- and quantum } \\
\text { dots-loaded TPGS-Tf }\end{array}$ & $\begin{array}{l}\text { Brain-targeted imaging and } \\
\text { chemotherapy }\end{array}$ & $\begin{array}{l}\text { The theranostic agent can effectively cross the blood-brain barrier } \\
\text { and show fluorescence in the brain of rats. }\end{array}$ & $\begin{array}{l}\text { Sonali Singh et al., } \\
2016\end{array}$ \\
\hline Transferrin & Tf-IR780 NPs & $\begin{array}{l}\text { NIR imaging and PDT/PTT } \\
\text { for Tfr-overexpressed } \\
\text { tumors }\end{array}$ & $\begin{array}{l}\text { The CT26 tumor and liver can be clearly visualized at } 2 \mathrm{~h} \\
\text { post-injection, while only the CT26 tumor can be clearly visualized } \\
\text { at } 12 \mathrm{~h} \text { post-injection. After injection of the NPs followed by } \\
808 \mathrm{~nm} \text { laser irradiation, the CT26 tumor was effectively } \\
\text { suppressed, and no significant adverse effect was observed. }\end{array}$ & Wang et al., 2016a \\
\hline Transferrin & $\begin{array}{l}\text { Iron-dependent } \\
\text { artesunate-loaded Tf-hollow } \\
\text { mesoporous CuS NPs }\end{array}$ & $\begin{array}{l}\text { PA imaging and } \\
\text { chemo-phototherapy for } \\
\text { Tfr-overexpressed tumors }\end{array}$ & $\begin{array}{l}\text { The NPs can be effectively used for tumor imaging, and } \\
\text { peritumoral injection is more conducive to tumor imaging than i.v. } \\
\text { injection. After peritumoral injection of the NPs followed by } 808 \mathrm{~nm} \\
\text { laser irradiation, the tumor was effectively suppressed. }\end{array}$ & Hou et al., 2017 \\
\hline Transferrin & Holo-Tf-ICG & $\begin{array}{l}\text { Fluorescence and PA } \\
\text { dual-modal imaging and } \\
\text { PTT for glioma }\end{array}$ & $\begin{array}{l}\text { The theranostic agent can provide high spatial resolution } \\
\text { fluorescence and PA imaging for visualization of the distribution of } \\
\text { ICG in subcutaneous- and orthotopic- brain tumors. After i.v. } \\
\text { injection of the theranostic agent followed by } 808 \mathrm{~nm} \text { laser } \\
\text { irradiation, the U87 tumor was effectively suppressed, and no } \\
\text { significant adverse effect was observed. }\end{array}$ & Zhu et al., 2017 \\
\hline Transferrin & $\begin{array}{l}\text { Iron oxide NPs conjugating } \\
\text { Tf, TAT peptide and Cy7 }\end{array}$ & $\begin{array}{l}\text { Simultaneous cancer cell } \\
\text { nuclear targeting, NIR/MR } \\
\text { imaging and synchronous } \\
\text { PTT }\end{array}$ & $\begin{array}{l}\text { The theranostic agent can be used for the A549 tumor imaging, } \\
\text { and the best imaging effect is at about } 8 \mathrm{~h} \text { postinjection. After i.v. } \\
\text { injection of the theranostic agent, the A549 tumor was effectively } \\
\text { eliminated, and no significant adverse effect was observed. }\end{array}$ & Peng et al., 2017 \\
\hline Transferrin & $\begin{array}{l}\text { Protoporphyrin IX-loaded } \\
\text { UCNP@Tf NPs }\end{array}$ & $\begin{array}{l}\text { NIR light induced PDT of } \\
\text { cancer cells and } \\
\text { luminescence bioimaging }\end{array}$ & $\begin{array}{l}\text { Under } 980 \text { nm laser irradiation, the NPs can not only kill } \\
\text { MDA-MB-231 cells by PDT, but also show clear bright green in } \\
\text { MDA-MB-231 cells. }\end{array}$ & Wang et al., $2017 \mathrm{a}$ \\
\hline Silk & $\begin{array}{l}\text { NIR-797-labeled } \\
\text { anti-EGFR-iRGD-PTX-silk } \\
\text { fibroin NPs }\end{array}$ & $\begin{array}{l}\text { Fluorescence } \\
\text { imaging-guided } \\
\text { chemotherapy }\end{array}$ & $\begin{array}{l}\text { In HeLa tumor-bearing mice, the NPs can be used for the tumor } \\
\text { and liver fluorescence imaging, and the maximum fluorescence } \\
\text { intensity in tumor and liver tissues arose at } 24 \mathrm{~h} \text { post-injection. } \\
\text { After tail vein injection of the NPs, the HeLa tumor was eliminated, } \\
\text { and no significant adverse effect was observed. }\end{array}$ & Bian et al., 2016 \\
\hline Silk & $\begin{array}{l}\text { Nanodiamonds-silk } \\
\text { fibroin-DOX }\end{array}$ & $\begin{array}{l}\text { Fluorescence tracking and } \\
\text { chemotherapy }\end{array}$ & - & Khalid et al., 2016 \\
\hline Silk & $\begin{array}{l}\text { DOX-loaded sericin/dextran } \\
\text { composite hydrogel }\end{array}$ & $\begin{array}{l}\text { Drug monitoring and } \\
\text { chemotherapy }\end{array}$ & $\begin{array}{l}\text { After subcutaneous injection, the photoluminescence of hydrogel } \\
\text { is long-term stable in C57BL/6 mice without being quenched. } \\
\text { After injection the hydrogel into the vicinity of the B16-F10 tumor, } \\
\text { the tumor was effectively suppressed, and no significant } \\
\text { differences in body weight were observed. }\end{array}$ & Liu et al., 2016 \\
\hline
\end{tabular}




\section{TABLE 1 | Continued}

\begin{tabular}{|c|c|c|c|c|}
\hline Protein & Formulation & Application & Key outcomes of in vitro/in vivo study & References \\
\hline Zein & $\begin{array}{l}\text { Cy5-labeled } \\
\text { hydroxycamptothecin } \\
\text { @AuNPs-Zein-folate- } \\
\text { conjugated } \\
\text { polydopamine }\end{array}$ & $\begin{array}{l}\text { Active targeting in drug } \\
\text { delivery and cell imaging }\end{array}$ & $\begin{array}{l}\text { The increase of fluorescence signals from the KB tumors was } \\
\text { accompanied by the sharp decline in normal tissues at } 3 \mathrm{~h} \text { post } \\
\text { injection, and the fluorescence signals at the tumor remains } \\
\text { basically constant within } 24 \mathrm{~h} \text {. After i.v. injection of the theranostic } \\
\text { agent, the KB tumor was effectively eliminated, and no acute } \\
\text { toxicity was observed. }\end{array}$ & Wang et al., 2017b \\
\hline Lipoprotein & $\begin{array}{l}\text { Boron/Gd agent lipoprotein } \\
\text { adducts }\end{array}$ & $\begin{array}{l}\text { MRI/Boron Neutron Capture } \\
\text { Therapy }\end{array}$ & $\begin{array}{l}\text { After i.v. injection of the adducts, high MRI signal intensity was } \\
\text { observed in the liver and in the tumor region. 30-40 days after } \\
\text { neutron irradiation, the tumor growth of mice was negligible. }\end{array}$ & Alberti et al., 2015 \\
\hline Lactoferrin & $\begin{array}{l}\text { Zinc-doped } \\
\mathrm{Fe}_{3} \mathrm{O}_{4} \text {-saturated bovine } \\
\text { lactoferrin }\end{array}$ & $\begin{array}{l}\text { Real-time cancer imaging } \\
\text { and simultaneous } \\
\text { cancer-targeted therapy }\end{array}$ & $\begin{array}{l}\text { Orally fed the theranostic agent gave a bright dark }\left(T_{2}\right) \text { contrast at } \\
\text { the Caco } 2 \text { tumor site. Oral administration of the theranostic agent } \\
\text { exhibited significant antitumor efficacy and a nontoxic and } \\
\text { biocompatible nature in the human breast cancer and xenograft } \\
\text { colon tumors. }\end{array}$ & $\begin{array}{l}\text { Kamalapuram } \\
\text { et al., } 2016\end{array}$ \\
\hline Lactoferrin & $\begin{array}{l}\mathrm{Fe}_{3} \mathrm{O}_{4} \text {-saturated bovine } \\
\text { lactoferrin }\end{array}$ & $\begin{array}{l}\text { Real-time imaging and } \\
\text { monitoring the effect of } \\
\text { drugs in real time }\end{array}$ & $\begin{array}{l}\text { Oral administration of the theranostic agent exhibited significant } \\
\text { antitumor efficacy in the human breast cancer tumor. }\end{array}$ & Kanwar et al., 2016 \\
\hline
\end{tabular}

fluorescence quantum yield at $600 \mathrm{~nm}$ excitation and an even high absorbance whereas low fluorescence quantum yield under $808 \mathrm{~nm}$ excitation, showing a great performance in NIR imaging and PTT at separated wavelengths. A gadolinium was further fabricated on HSA-IR825 for dual-modal imaging-guided PTT of tumor in a follow-up study (Figure 2B) (Chen et al., 2014a). In this work, HSA was conjugated with the Gd(III) compound of diethylenetriamine pentaacetic acid, and further complexed with IR825, to form HAS-Gd-IR825 complex. The HAS-Gd-IR825 complex has great fluorescence and NIR absorbance, impressive $T_{1}$ relaxivity of $4.82 \mathrm{mM}^{-1} \mathrm{~s}^{-1}$. More recently, a gemcitabine functionalized HSA-IR780 agent was reported for chemotherapy and imaging-guided PTT of tumor (Han et al., 2017). HSA was first conjugated with gemcitabine via cathepsin B cleavable peptide GFLG, and then mixed with IR780 dye at the molar ratio of 1:1. IR780 could bound to HSA via hydrophobic interactions.

For above systems, the NIR dyes were bound to the HSA via non-covalent interactions, possibly causing dye leakage during in vivo circulation (Rong et al., 2015). To address this problem, heptamethine CySCOOH dye (a NIR cyanine dye) was covalently conjugated to the lysine residues of HSA (Rong et al., 2015) via a modified EDC/NHS reaction for effective photoacoustic (PA), NIR fluorescence, thermal multimodality imaging and PTT. Such conjugation, compared with free $\mathrm{CySCOOH}$ dye under the identical conditions, resulted in higher PTT efficacy, tumor accumulation and longer circulation. Moreover, the maleimide group can be rapidly and selectively bound to the Cys34 residue of HSA via a Michael addition reaction. Recently, the Michael addition reaction was employed to couple fluorescent dye Cy7 to Cys34 position of HAS (Lisitskiy et al., 2017). And meantime, the chemotherapeutic agent pTFT (5-trifluoromethyl-2'-deoxyuridine 5 -monophosphate) was coupled to lysine residues of HSA via a redox and $\mathrm{pH}$ dual-sensitive linker. The conjugates could not only serve as an optical and ${ }^{19} \mathrm{~F}$ MR imaging, but also be applied for delivery of chemotherapeutics.

\section{HSA-Based Complexes}

HSA has an effective diameter of $7.2 \mathrm{~nm}$. Yet nanocarriers with sizes of $100-200 \mathrm{~nm}$ are well known to tend to accumulate in tumor tissues more efficiently via the enhanced permeability and retention (EPR) effect (Peer et al., 2007). Besides, theranostic agents usually require more functional ingredients to expand the application. Accordingly, great efforts have been devoted to design HSA-based complexes with appropriate sizes and more characteristics, to establish multifunctional HSA-based theranostics. For example, melanin and paclitaxel (PTX)-loaded HSA nanoparticles (HMP-NPs) with size of ca. $192 \mathrm{~nm}$ were fabricated with a desolvation-crosslinking method (Mo et al., 2007; Sim et al., 2015). The HMP-NPs showed effective PA signal intensity in the tumor site and the capability to tumor chemotherapy with long circulation time, as confirmed by in vivo experiments. In addition, the desolvation-crosslinking method was adopted to form HSA-based NPs (Pt(IV)-probe@HSA) for theranostic application ( $\mathrm{Li}$ et al., 2015). In this work, the HSA NPs surface were conjugated with Pt(IV) antitumor prodrug, NIR fluorophore Cy5, and quencher Qsy21. The Pt(IV)-probe@HSA can not only selectively trigger the localized activation of $\mathrm{Pt}(\mathrm{IV})$ prodrug, but also enable real-time tumor cell imaging with high resolution.

For the above systems, glutaraldehyde is employed to stabilize the HSA NPs, whereas possible aldehyde residue may cause some side effects for in vivo applications (Fürst and Banerjee, 2005). To address this problem, some facile methods involving no toxic chemicals or exogenous cross-linkers have been broadly adopted in the preparation (Sheng et al., 2014; Hu et al., 2016). As an example, HSA-ICG NPs was developed with an average hydrodynamic diameter of nearly $75 \mathrm{~nm}$ based on the intermolecular disulfide bond cross-linking within HSA, for imaging-guided PDT and PTT treatments (Sheng et al., 2014). In this work, they first broke up the intramolecular disulfide bonds of HSA with the endogenous reducing agent glutathione, and then fabricated the HSA NPs with a desolvation method. A 

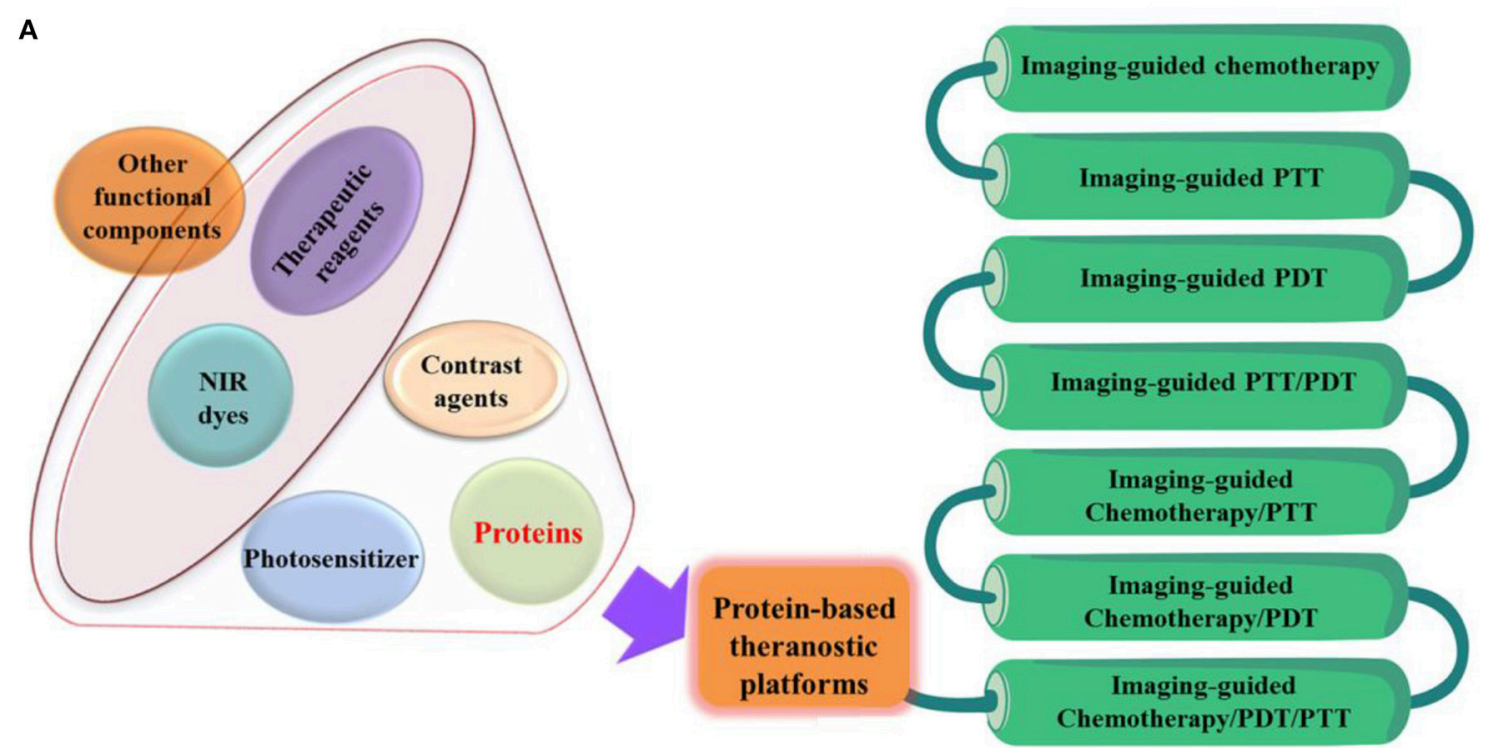

B

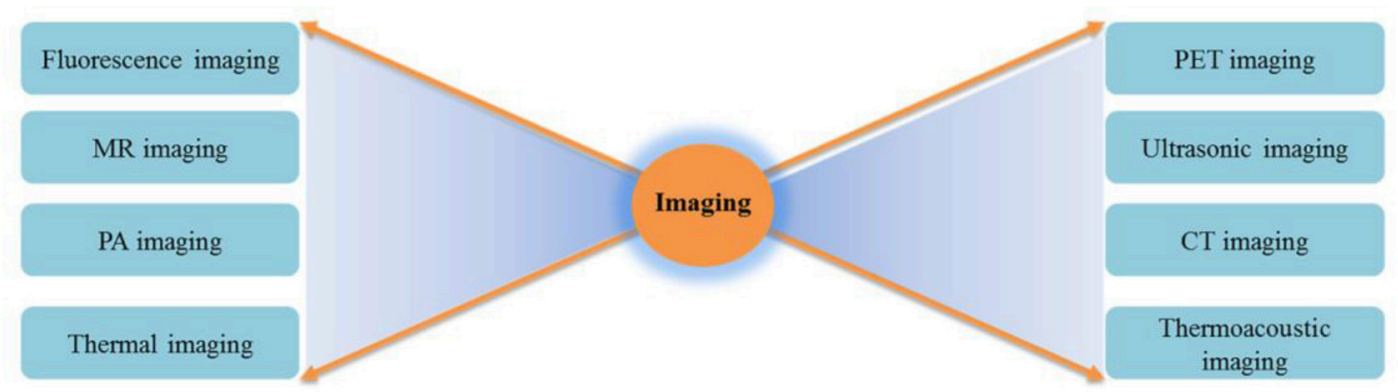

FIGURE 1 | (A) Engineering of protein-based nanoformulations as cancer theranostic platforms. (B) A series of imaging technologies are incorporated in the theranostic platforms.

similar strategy was also adopted in their recent work to fabricate HSA nanoassemblies (NAs) with photosensitizer chlorin e6 (HSA-Ce6 NAs) for multi-modal imaging-guided PDT (Hu et al., 2016). The proposed HSA-Ce6 NAs had a diameter of ca. $100 \mathrm{~nm}$, excellent tumor selectivity, promising triple-modal (fluorescence, PA and MR) imaging, and effective PDT properties.

Another method proposed by Liu's group not introducing exogenous cross-linkers is to fabricate HSA-based multifunctional theranostic NPs with drug-induced protein assembly strategy (Chen et al., 2015a). In this work, a multifunctional "Abraxane-like" theranostics agent was formulated through simply incorporating three clinical approved agents, ICG, PTX and HSA together (Figure 2C). In this formulation, the NIR fluorescence imaging, thermal imaging, PTT and chemotherapy were efficiently combined. Accordingly, a synergistic therapeutic effect is demonstrated in treating metastatic and subcutaneous breast tumors. As a result, the strategy is enriched to design tumor-targeted theranostics agent for multimodal imaging-guided therapy of tumors (Chen et al., 2015b). HSA is pre-modified in their design, with either a tumortargeting acyclic Arg-Gly-Asp (RGD) peptide (HSA-RGD) or a photosensitizing agent Ce6 (HSA-Ce6). The anticancer drug PTX is then employed to induce the self-assembly of HSA-RGD and HSA-Ce6 to fall into two different NPs. After incorporation of manganese(II), both of NPs could be tracked by MR imaging and fluorescence imaging, which can be adopted for combinatorial cancer PDT and chemotherapy. Similarly, photosensitizer agent iron (II) phthalocyanine (FePc)-induced HSA self-assembly, is employed in a recent study to fabricate multifunctional HSA-FePc NPs for PA imaging-guided PTT (Jia et al., 2017). The as-prepared HSA-FePc NPs exhibited high stability, high PA imaging quality, efficient PTT treatment, and low long-term toxicity in vivo.

\section{HSA-Coated Complexes}

PTX-loaded HSA NPs were conjugated to the surface of porphyrin microbubbles for cancer theranostics (Moon et al., 2015). In this system, porphyrin microbubbles were fabricated using porphyrin-phospholipid conjugates to simultaneously intensify ultrasound and PA signal. The developed multifunctional theranostics agent is high sensitive in PA and ultrasound imaging, and effective in delivery 
A

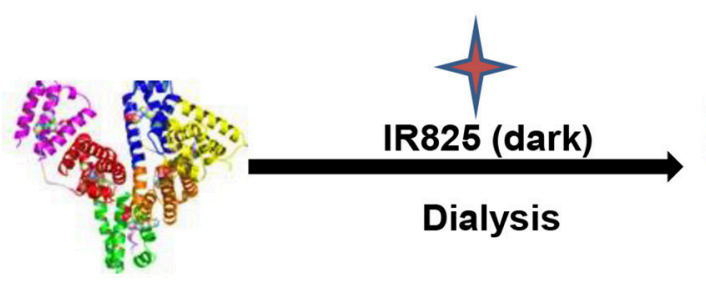

HSA

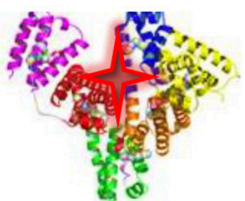

HSA-IR825

(bright)

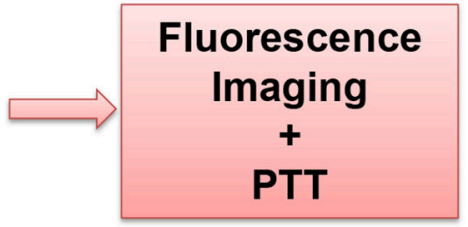

$\sim 10 \mathrm{~nm}$

B
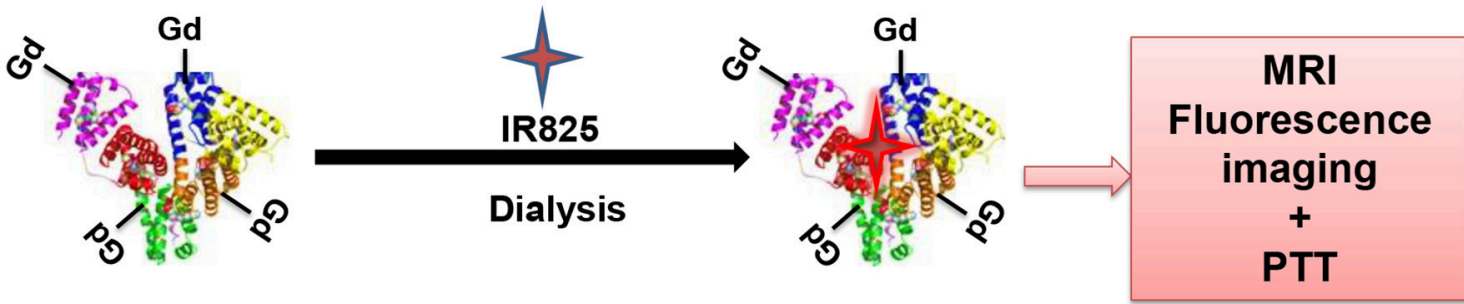

HSA-Gd-IR825

$\sim 10 \mathrm{~nm}$

C
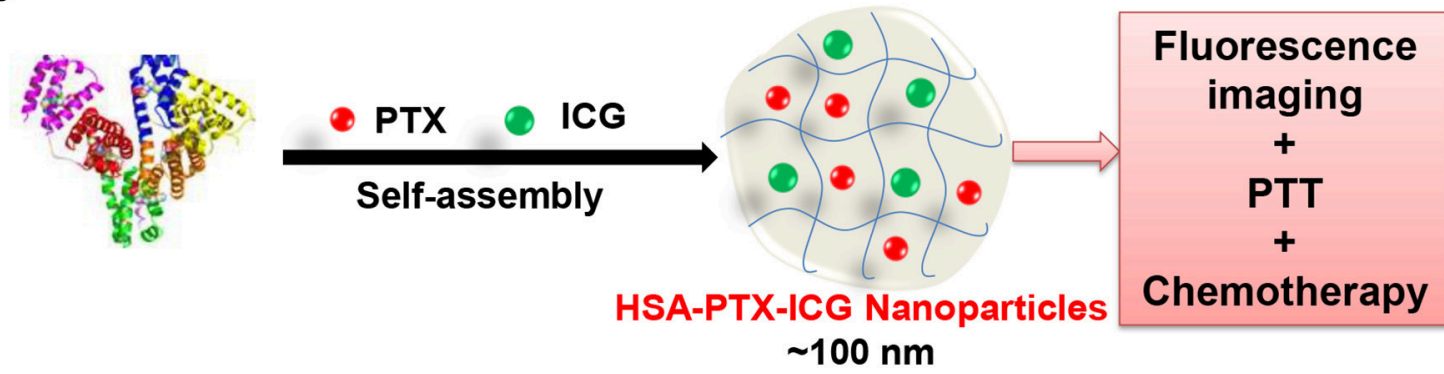

FIGURE 2 | Schematic illustration of the fabrication of HAS-IR825 complex (A) (Chen et al., 2014c), HAS-Gd-IR825 complex (B) (Chen et al., 2014a), and HSA-ICG-PTX nanoparticles (C) (Chen et al., 2015a).

of anticancer drug PTX to a tumor site. HSA-coated superparamagnetic iron oxide NPs were presented more recently, which can absorb pulsed microwave energy and transform efficiency into shockwave with the thermoelastic effect besides using as MR contrast agents (Wen et al., 2017).

\section{BSA for Cancer Theranostics Individual BSA-Dye Complexes}

BSA consists of multiple hydrophobic binding sites, and can naturally serve as a carrier of numerous small NIR dyes agents. Squaraine (SQ) was selectively bound to hydrophobic domain of BSA via hydrogen bonding and hydrophobic interactions with 80-fold enhanced fluorescence intensity (Gao et al., 2014). Based on this, a supramolecular adducts of SQ and BSA (SQ@BSA) was constructed and served as PTT agent and effective bioimaging probe simultaneously. In addition, folic acid (FA) functionalized SQ@BSA (SQ@BSA-FA) has additional functions, e.g., monitoring the time-dependent bio-distribution of adducts and targeting tumor sites. ICG, an FDA-approved NIR dye, can be adsorbed on BSA for NIR fluorescence imaging, PTT and PDT as excited by single-wavelength (Chen and Liu, 2016). Besides, BSA-based theranostics system covalently modified with NIR dyes has been reported (Lee et al., 2016). For example, a zinc-coordinated $\mathrm{pH}$-sensitive theranostics agent is reported, consisting of two types of polyethylene glycol-BSA-imidazole covalently modified with either BHQ-3 quencher (NIR dark quencher) or Cy5.5 dye (donor NIR dye). At pH 5.0 (e.g., endo/lysosomes in cancer cells), the theranostics agent was disassembled rapidly, and emitted strong NIR fluorescence (Lee et al., 2016).

\section{BSA-Based Complexes}

Besides bound to NIR dyes, BSA can be further engineered with other functional agents via complexation, such as gadolinium (Wei et al., 2016; Yang et al., 2016; Chen et al., 2017a; Zhou et al., 2017), manganese (Liu et al., 2017; Pan et al., 2017) and graphene's derivatives (Sheng et al., 2013). For 
example, hollow BSA was employed to fabricate a sizetunable $\mathrm{Gd}_{2} \mathrm{O}_{3} @ \mathrm{BSA}$ conjugating $\mathrm{Ce} 6$ theranostics agent for MR imaging-guided PDT and PTT (Figure 3) (Zhou et al., 2017). Notably, the BSA nanoreactor can not only effectively regulate the longitudinal relaxivity of $\mathrm{Gd}_{2} \mathrm{O}_{3}$, but conjugate readily with photosensitizers. A facile strategy is presented, adopting BSA as a biotemplate at physiological temperature, to construct a biocompatible Gd-integrated CuS multifunctional theranostics agent (Gd:CuS@BSA) (Yang et al., 2016). The fabricated Gd:CuS@BSA theranostics agent possessed ultrasmall sizes (about $9 \mathrm{~nm}$ ), acceptable longitudinal $r_{1}$ relaxivity of 16.032 $\mathrm{mM}^{-1} \cdot \mathrm{s}^{-1}$, impressive temperature rise and intense PA signals under NIR irradiation. Recently, a multifunctional $\mathrm{MoS}_{2}-\mathrm{Gd}-$ BSA theranostics agent was fabricated through incorporating the good photothermal effect of $\mathrm{MoS}_{2}$ nanoflakes with the high longitudinal proton relaxivity of BSA-Gd complex via the amine reaction between carboxyl groups of $\mathrm{MoS}_{2}$ nanoflakes and amino groups of BSA-Gd (Chen et al., 2017a). The $\mathrm{MoS}_{2}-\mathrm{Gd}-$ BSA theranostics agent exhibits a strong NIR absorbance and high $r_{1}$ relaxivity, which are helpful for PA and $T_{1}$-weighted MR dual-modal imaging-guided PTT of cancer. Besides, a chemotherapeutic drug carmustine-encapsulated FITC-BSA NPs were prepared by desolvation/denaturation method and conjugated with a MR gadolinium(III) salt to form nanomedicine with dual imaging modalities (Wei et al., 2016).

At the identical stage, contrast agent Mn-based BSA complexes have been also reported for cancer theranostics (Liu et al., 2017; Pan et al., 2017). For example, a multifunctional BSA$\mathrm{MnO}_{2}$ theranostics agent was fabricated via a mimicking drugsubstrate interaction strategy, adopting BSA as both reductant

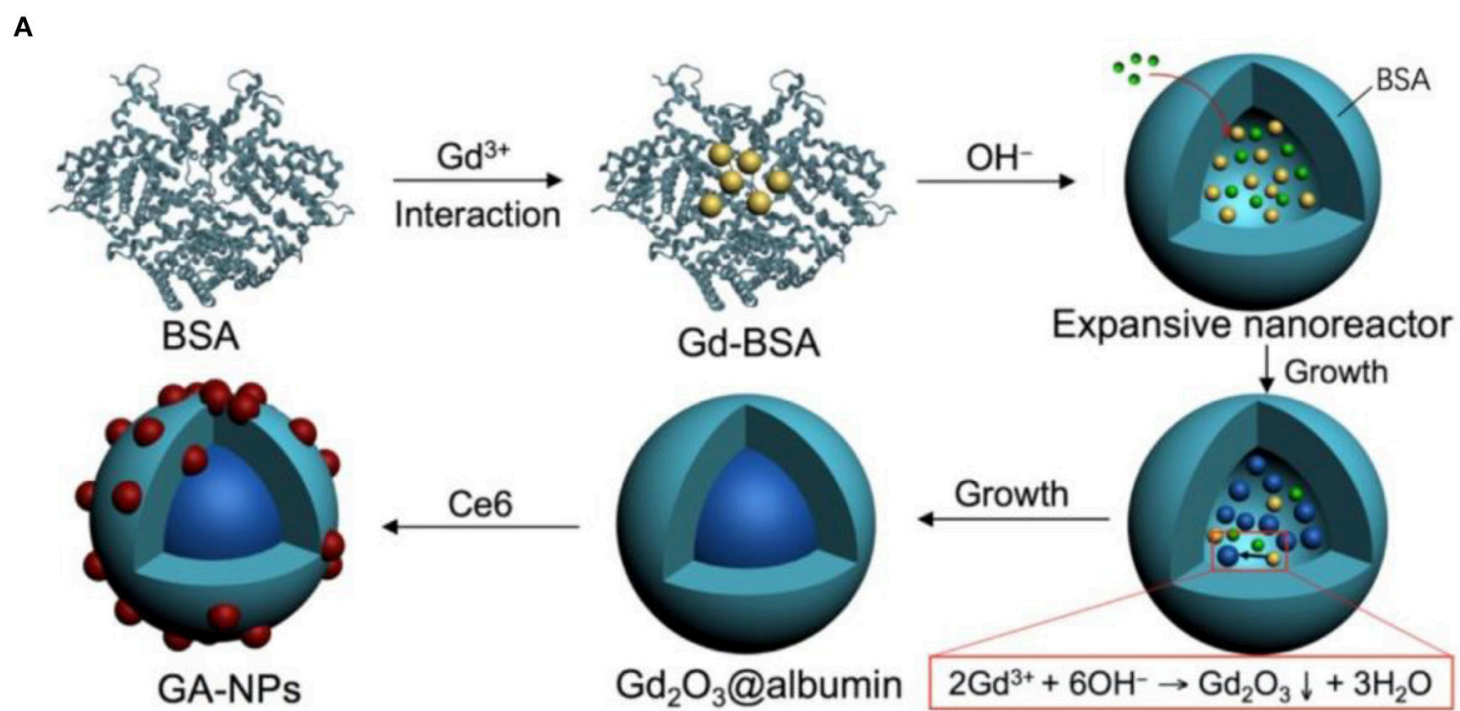

B
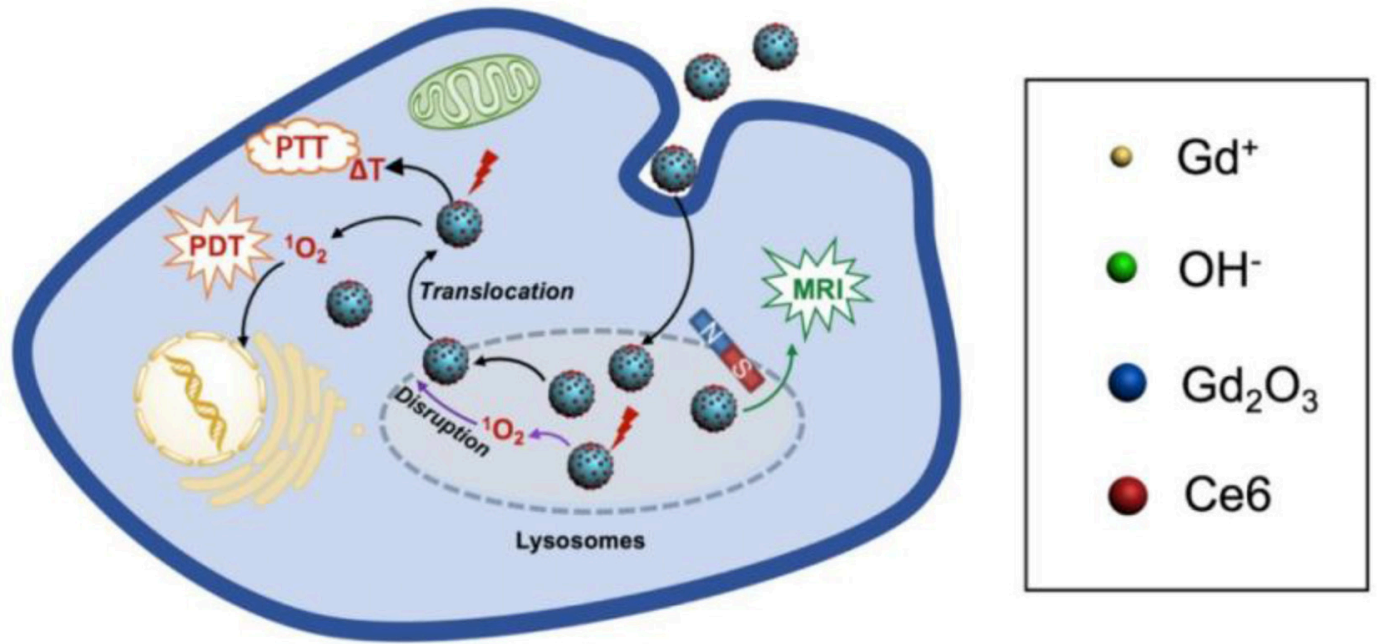

FIGURE 3 | Schematic illustration the synthesis of core-shell $\mathrm{Gd}_{2} \mathrm{O}_{3} @ \mathrm{BSA}$ conjugating Ce6 (A) for MRI-guided cancer photothermal therapy (PTT) and photodynamic therapy (PDT) (B). Reproduced with permission (Zhou et al., 2017). 
agent and template (Pan et al., 2017). It is noteworthy that ICG and PTX can be loaded on $\mathrm{BSA}-\mathrm{MnO}_{2}$ with a facile and energysaving mixing. The ICG/PTX-loaded $\mathrm{BSA}-\mathrm{MnO}_{2}$ theranostics agent could be adopted for MR imaging guided PTT and chemotherapy in vitro and in vivo.

Furthermore, a BSA-assisted synthesis route was developed to produce reduced graphene oxide (nano-rGO) theranostic agent (Sheng et al., 2013). The BSA functionalized nano-rGO displayed a high stability and low cytotoxicity, enabling PA imaging and PTT treatment without further surface modification. On that basis, a folate receptor active-targeted, $\mathrm{pH}$-responsive BSA-pheophorbide-a (PheoA) photosensitizer incorporated GO nanocarrier (PheoA + GO:FA-BSA-c-PheoA NC) is developed as an theranostic agent (Battogtokh and Ko, 2016). The theranostic agent carries a good $\mathrm{pH}$-responsive photosensitizer and generates a synergistic PTT and PDT effect against tumor by NIR irradiation.

\section{BSA-Coated Complexes}

BSA serves not only as a delivery platform to load various functional molecules, e.g., dyes and chemotherapy drugs, but also as a coating agent of other nanocarriers to increase the physiological stability, water-solubility and blood circulation time of theranostics systems. For example, BSA is employed to coat $\mathrm{NaGdY}_{4}$-based upconversion NPs (UCNPs), resulting in UCNP@BSA NPs possessing well stability and water-solubility in physiological environments (Chen et al., 2014b). And meantime, two different dyes, consisting of an IR825 dye and a Rose Bengal (RB) photosensitizer, can be effectively loaded onto the BSA shell layer of the UCNP@BSA system. It is noteworthy that the characteristic absorbance peak of RB complies well with the green emission peak of UCNPs (980 nm excitation), which effectively kills cancer cells by PDT. Therefore, the dual-dye loaded theranostics agent can be adopted for MR diagnostic, upconversion optical imaging, PDT as well as PTT both in vitro and in vivo. BSA-coated magnetite $\mathrm{Fe}_{3} \mathrm{O}_{4}$ core-shell structures with anticancer drug (gemcitabine) were developed, where BSA serving as the outer shell was further functionalized by the active targeted agent Anti-EGFR mab C225 (Wang et al., 2015). The theranostics agent can efficiently regulate doubletargeted thermochemotherapy against pancreatic tumor, monitor different cellular targeting by MR imaging, and distinguish various EGFR-expressing pancreatic tumor cells. On that basis, a BSA-coated magnetite $\mathrm{Fe}_{5} \mathrm{C}_{2}$ theranostics agent was developed with a high loading of antitumor drug doxorubicin (DOX) (Yu et al., 2016). Notably, the DOX can be released in acidic condition and irradiated by NIR. In this regard, the theranostics agent serves as a smart nanoplatform for $\mathrm{MR}$ imaging, effective chemotherapy and PTT. A pH-responsive proteinpolymer bioconjugate-coated theranostics agent consisting of a superparamagnetic magnetite $\mathrm{Fe}_{3} \mathrm{O}_{4}$ core, BSA-poly(ethylene glycol) (PEG) shell and anticancer drug DOX were presented for combined MR imaging diagnostics and chemotherapy (Semkina et al., 2015). A BSA-poly( $\varepsilon$-caprolactone) bioconjugate-coated upconversion theranostics agent is constructed with the similar preparation method for simultaneous cancer cell imaging, PDT, and chemotherapy (Dong et al., 2016). BSA stabilized Prussian blue (PB) NPs were fabricated, and ICG molecules were further attached non-covalently by a biocompatible and simple method (Sahu et al., 2016). Here, PB serves as a MR contrast enhancer. Accordingly, the multifunctional theranostics system could provide dual mode MR signal and NIR fluorescence imaging as well as combined therapy with PDT and PTT. A pH-responsive $\mathrm{Au}-\mathrm{BSA}$ core/shell theranostics agent consisting of Au core, BSA shell that conjugated with DOX and FA was developed recently, which manifested tumor computed tomography (CT) imaging application and targeted cancer therapy (Huang et al., 2017).

Albumin-based NPs could be synthesized by using albumin as a scaffold, template, or stabilizer, and conjugating to polymers, drugs, and contrast agents. Covalent and non-covalent conjugation or assembly were employed. Due to the success of Abraxane, researchers preferred the non-convalent self-assembly. However, NPs prepared using the non-convalent strategy will vary batch to batch, which need to be overcome in the future studies (An and Zhang, 2017).

\section{FERRITIN-BASED NANOFORMULATIONS}

\section{Ferritin and Its Properties}

Ferritin counts as an abundant protein in circulation, existing in intracellular and extracellular compartments. Ferritin is a 450 $\mathrm{kDa}$ hollow nanocage with internal and external dimensions of 8 and $12 \mathrm{~nm}$, respectively (Banyard et al., 1978). It accumulates and stores approximately 4,500 iron atoms in a non-toxic whereas bioavailable form (Alkhateeb and Connor, 2013). In mammals, each ferritin protein consists of 24 subunits self-assembled into a spherical symmetrical protein shell (Alkhateeb and Connor, 2013). The ferritins from eukaryotes are produced by selfassembly of two subunit types, i.e., L-ferritin chain (19 kDa) and $\mathrm{H}$-ferritin chain $(21 \mathrm{kDa})$. The $\mathrm{H}$-chain is centered by an iron oxidase center, required to oxidize $\mathrm{Fe}(\mathrm{II})$ to $\mathrm{Fe}$ (III), whereas the L-chain without ferroxidase activity nucleates iron (Bellini et al., 2014). Ferritin counts as a multifunctional protein with iron storage and metabolism. Ferritin is critical for angiogenesis, proliferation and immunosuppression, as demonstrated by growing number of evidence (Alkhateeb and Connor, 2013).

Ferritin is a ubiquitous protein robust extremely: it can be reversibly disassembled in the extremely acidic $\mathrm{pH}(\mathrm{pH} 2-3)$ or basic $\mathrm{pH}(\mathrm{pH} 10-12)$ and can be heated at $80^{\circ} \mathrm{C}$ exerting no deleterious effects (Truffi et al., 2016). These properties as well as its biocompatibility and biodegradability make it a suitable candidate for cancer theranostics (Bhushan et al., 2014).

\section{Ferritin for Cancer Theranostics}

The ferritin not only provides a reaction vessel to fabricate numerous non-native metallic NPs inside its core, but also serves as a nanocarrier for various applications (Bhushan et al., 2014). For example, $\mathrm{Zn}$ hexadecafluorophthalocyanine $\left(\mathrm{ZnF}_{16} \mathrm{Pc}\right)$, a potent hydrophobic photosensitizer, is well encapsulated into the Cys-Asp-Cys-Arg-Gly-Asp-Cys-Phe-Cys (RGD4C)-modified ferritins (P-RFRTs) with a loading rate as high as $\sim 60 \mathrm{wt} \%$ for effective PDT (Zhen et al., 2013b). The P-RFRTs were further conjugated with ZW800 (a NIR dye molecule) in this work to better track P-RFRTs particles. With the identical 
approach, the DOX-loaded RGD4C-modified ferritin was also reported (Zhen et al., 2013a). A self-assembly encapsulation strategy based on step-wise change of $\mathrm{pH}$ was developed in another report to fabricate ferritin NPs with NIR dye IR820 for fluorescence/PA multimodal imaging-guided PTT (Huang et al., 2014). The IR820-loaded ferritin nanocages can effectively treat and diagnose cancer adopting two different excitation wavelengths, i.e., $550 \mathrm{~nm}$ for high quantum-yield fluorescence imaging, and $808 \mathrm{~nm}$ for PA imaging and effective PTT. Additionally, CuS was fabricated inside the cavity of ferritin nanocages with a biomimetic and straightforward synthesis strategy (Wang et al., 2016b). The CuS-ferritin has strong NIR absorbance, high photothermal conversion efficiency, good biocompatibility and distinct PA contrast,. Notably, the ${ }^{64} \mathrm{CuS}-$ ferritin theranostic system, as incorporated with radionuclide ${ }^{64} \mathrm{Cu}$, also served as an excellent PET imaging agent.

The higher level of L-ferritin in tumor versus normal tissue has been observed in some malignancies tissues like breast cancer, colon cancer, pancreatic cancer and testicular seminoma (Alkhateeb and Connor, 2013). High amount of L-ferritin is usually associated and bound with intensified expression of the $\mathrm{L}$-ferritin receptor that mediates ferritin endocytosis. The higher the expression of L-ferritin receptors, the more intensified uptake of L-ferritin in breast cancer MCF-7 cells (Geninatti Crich et al., 2015). Based on this, a ferritin-based nanotheranostic system has been further developed to simultaneously deliver a MR contrast agent GdHPDO3A and a natural anticancer molecule curcumin (Geninatti Crich et al., 2015). The theranostics system selectively delivered therapeutic and imaging agents to breast cancer cells. In a follow-up study, L-ferritin was found to target breast cancer stem cells (Conti et al., 2016). In this regard, ferritin was further exploited to deliver curcumin and the GdHPDO3A MR contrast agent simultaneously for breast cancer stem cells (Conti et al., 2016). In a very recent report (Turino et al., 2017), multifunctional theranostics system was developed through coating poly (lactic-co-glycolic acid) NPs (PLGA NPs) with L-ferritin to increase their targeting capability to breast cancer MCF-7 cells. The L-ferritin functionalized PLGA NPs loaded with an amphiphilic Gd based MR contrast agent and PTX for MR imaging guided chemotherapy. In addition to this, ferritin coating makes PLGA NPs more stable, thus avoiding the non-specific and fast release of therapy/diagnosis agents before reaching the targeted sites.

Hollow structure make the ferritin become an ideal carrier, however, after loading therapeutic agents, the slight change in conformation and activity might take place. The toxicity of ferritin-based NPs should be studied carefully as other NPs. Also, the surface-modified ferritins may be recognized as foreign substances. Therefore, when surface targeting ligands were needed, the grafting density are important factors to be considered.

\section{GELATIN-BASED NANOFORMULATIONS}

\section{Gelatin and Its Properties}

Gelatin is a polyampholyte protein having both anion and cation along with hydrophobic groups (Elzoghby, 2013). Gelatins have repeating sequences of proline, alanine, and glycine amino acid triplets, which are essential for gelatin (Sahoo et al., 2015). They are obtained from alkaline-, acid- or enzymatic- hydrolysis of collagen. These chemically treated gelatins have varying isoelectric points, i.e., 4.5-6.0 for alkaline treatment and 7-9 for acid treatment (Patel et al., 2008; Ninan et al., 2011). In addition, anticancer agent release profiles from gelatin protein can be controlled through changing the molecular weight, gelatin source and the crosslinking degree (Foox and Zilberman, 2015). Gelatin is natural, biocompatible, biodegradable, water permeable, nontoxic, and soluble in water (Nezhadi et al., 2009). As a delivery carrier of therapeutic/diagnostic agents, gelatin has been revealed multifunctional properties, enabling the development and design of versatile theranostics.

\section{Gelatin for Cancer Theranostics}

Gelatin has native hydrophobic and hydrophilic segments in each single polypeptide chain, enabling itself a conducive coating agent for various metal NPs (Li et al., 2013; Cheng et al., 2014; Tran et al., 2017b). For example, a theranostic system was developed through coating iron oxide NPs with selfassembled gelatin (abbreviated as AGIO) (Li et al., 2013). In the meantime, calcium phosphate $(\mathrm{CaP})$ and anticancer DOX could be loaded on gelatin by electrolytic co-deposition technique. The fabricated AGIO@CaP-DOX NPs had efficient MR contrast, superior cytocompatibility and potent cellular internalization toward HeLa cells. A gelatin coated multifunctional nanosystem, with oleylamine-coated $\mathrm{Fe}_{3} \mathrm{O}_{4}$ NPs core, amphiphilic gelatin shell, and fluorescent labeling molecules FITC and antitumor platinum(IV) prodrug, was elaborated for fluorescence and MR imaging guided chemotherapy (Cheng et al., 2014). Most recently, oleic acid and gelatin were adopted to modify a silicacoated iron oxide magnetic NPs, which was demonstrated to encrease biocompatibility and solubility of iron oxide magnetic NPs and facilitate treatment-response monitoring of the tumors (Tran et al., 2017b). Particularly, the oleic acid and gelatin coated NPs enables the hydrophobic anticancer drug PTX to be loaded into the lipophilic oleic acid-gelatin shell. The synthesized theranostic system have high $r_{2}$ value, low cellular toxicity, high drug delivery efficacy and well anticancer efficacy in vitro. The pharmacokinetics, bio-distribution, tumor diagnostic and antitumor efficacy of the theranostic system in vivo were studied in a follow-up study to further confirm its potential in clinical applications (Tran et al., 2017a).

Beside iron oxide NPs, gold NPs are commonly coated with gelatin to increase their stability and biocompatibility. For example, a gelatin-coated gold NP-based nanostructure was developed for fluorescence imaging-guided chemotherapy (Tsai et al., 2016). The gelatin was firstly covalent conjugated with DOX, and then coated onto the epigallocatechin gallate (EGCG)-functionalized Au NPs. Here, DOX serves both as an anticancer drug and a fluorescent indicator. The attained DOX-gelatin/EGCG Au NPs exert an apparent inhibitory effect on the proliferation of human prostate cancer cells (PC-3) and can trace the intracellular enzyme-induced release of DOX through measuring the recovery of the DOX fluorescence signal. The covalent conjugation of DOX to nanocarriers may 
cause problems, e.g., insufficient in vivo release and decreased drug activity (Suarasan et al., 2016). A new temperatureand $\mathrm{pH}$-responsive theranostic system was developed on the basis of DOX non-covalently bound to biosynthesized gelatin-coated Au NPs (DOX-AuNPs@gelatin) (Suarasan et al., 2016). The fabricated DOX-AuNPs@gelatin would be an ideal agent for cancer theranostics based on its good biocompatibility, high DOX loading capacity via non-covalent complexation and effective DOX release under the tumor environment.

Recently, angiopep-2 modified gelatin-based core-shell NPs (Angio-DOX-DGL-Gel-NP) have been designed to increase the tumor targeting efficiency, tumor retention and tumor penetration (Hu et al., 2015). In this system, the shell consisted of dendrigraft poly-lysine linked with angiopep-2 and DOX, whereas the core was made up of gelatin NPs degraded by matrix metalloproteinase-2. Fluorescence imaging-guided chemotherapy showed enhanced antitumor effects in vitro and in vivo,

Gelatins are used as carriers in versatile drug delivery systems, form nanoparticles to microparticles (Foox and Zilberman, 2015). Small drug molecules or large bioactive molecules were easily entrapped into gelatins and released in a controlled manner. However, the cancer theranostic platforms based on gelatin didn't attract much attention. In our opinion, the gelatin-based NPs are promise cancer theranostics, especially in oral administration and brain delivery.

\section{TRANSFERRIN-BASED NANOFORMULATIONS}

\section{Transferrin and Its Properties}

Transferrin is a monomeric glycoprotein with 679 amino acids and a large molecular weight of approximately $79 \mathrm{kDa}$ (Parkkinen et al., 2002; Gomme et al., 2005). The molecule is protected by 3 carbohydrate side chains, one of which is O-linked (Ser-32) and the other are N-linked (Asn-413 and Asn-611) (Gomme et al., 2005). The polypeptide chain falls into two structurally similar lobes, known as the C-lobe (343 amino acids) and Nlobe (336 amino acids), which are connected by a short linear spacer sequence (Brandsma et al., 2011). Each lobe consists of one reversibly binding site for ferric iron with nearly $10^{22} \mathrm{M}^{-1}$ affinity at $\mathrm{pH} 7.4$ (Aisen et al., 1978). The major biological function of transferrin is to distribute and control circulating Fe, which is required for numerous biological processes, including cellular metabolism and proliferation, DNA synthesis, electron transfer, and oxygen transport (Dufès et al., 2013; Tortorella and Karagiannis, 2014). Particularly, transferrin specifically binds transferrin receptors (TfRs) on cell surface, forming a transferrin-TfR complex, and gets internalized by receptormediated endocytosis (Szoke and Panteghini, 2012; Dufès et al., 2013). Meantime, overexpression of TfRs has been observed in various cancer cells, including breast carcinoma, glioblastoma, melanoma, ovarian carcinoma and colon carcinoma (Calzolari et al., 2007; Tros de Ilarduya and Düzgüneş, 2013).

\section{Transferrin for Cancer Theranostics}

As a promising tumor targeting ligand, transferrin is frequently adopted to facilitate targeting delivery of theranostics. For example, transferrin-functionalized graphene quantum dots were developed to track and image tumor cells expressing the TfRs (Chen et al., 2013). In the meantime, the anticancer drug, DOX, was adsorbed on graphene surface in the system via hydrophobic interactions and $\pi-\pi$ stacking, which could be used for fluorescence imaging-guided chemotherapy. Another transferrin-conjugated PEGylated fluorescent nanodiamond with Dox payload was developed, and its targeting ability and chemotherapeutic potential were investigated in the human hepatoma (HepG2) cell lines with overexpression of TfRs and normal cell lines (L-02) with low-expression of TfR, respectively (Wang et al., 2014a). A transferrin conjugated theranostic micelles of D-alpha-tocopheryl PEG 1000 succinate (TPGS) were synthesized, containing both ultra-bright gold clusters as a model imaging agent and docetaxel as anticancer drug for synchronous cancer imaging and therapy (Muthu et al., 2015). The transferrin conjugated micelles, compared with the nontransferrin functionalized theranostic micelles, showed higher cellular uptake, higher cytotoxicity in MDA-MB-231-luc breast cancer cells. In a follow-up study, a transferrin decorated TPGS coated theranostic liposomes was further developed for targeted co-delivery of quantum dots and docetaxel for imaging-guided chemotherapy of brain cancer (Sonali Singh et al., 2016). Indeed, the transferrin decorated theranostic liposomes, compared with the non-transferrin targeted preparations, showed an improved and prolonged brain targeting of quantum dots and docetaxel. In addition, rattle-type theranostic NPs of mesoporous silica-coated $\mathrm{Fe}_{3} \mathrm{O}_{4}$ were develop by conjugating transferrin for targeted codelivery of NIR dye (Cy7) and hydrophobic anticancer drug PTX for NIR/MR bimodal imaging guided chemotherapy (Jiao et al., 2015).

Recently, transferrin and nuclear-targeted TAT peptide (YGRKKRRQRRR) conjugated magnetic NPs were proposed for PTT application (Peng et al., 2017). Magnetic NPs is preconjugated with transferrin and TAT peptide, and then bound to NIR dye Cy7. The theranostic system can efficiently target cancer cell nucleus and facilitate the NIR and MR imagingguided PTT. A core-shell theranostic system UCNP core $\left(\mathrm{NaYF}_{4}: \mathrm{Gd}^{3+}, \mathrm{Yb}^{3+}, \mathrm{Er}^{3+}\right)$ was developed, taking advantage of efficient NIR-to-visible up-conversion capability and increased tumor targeting ability and biocompatibility (Wang et al., 2017a). In the meantime, a clinically approved PTT agent, protoporphyrin IX, was loaded into the transferrin shell, being able to be drawn upon by cancer cells for efficient PDT with NIR irradiation and luminescence bio-imaging. A new strategy (diffusion molecular retention tumor targeting effect) was developed to fabricate tumor-targeted theranostic system for PA imaging-guided chemotherapy/photothermal with synergistic effect (Hou et al., 2017). In this study, hollow mesoporous CuS NPs (HMCuS NPs) were conjugated with transferrin and iron-dependent artesunate (AS), an effective anticancer drug. In this regard, the attained AS/TransferrinHMCuS NPs facilitated local drug accumulation and retention, targeted to breast cancer MCF-7 cells specially 
via TfR-mediated endocytosis, combined chemotherapyphototherapy synergistically, and eventually improved the anticancer effect.

Transferrin is not only a conducive targeting ligand, but also able to load imaging and/or therapeutic agents. For example, a simple, effective and safe self-assembly strategy was developed to fabricate transferrin NPs with NIR dye IR780 (TransferrinIR780 NPs) for targeted imaging and phototherapy of cancer (Wang et al., 2016a). The fabricated Transferrin-IR780 NPs had advantages on potent photo-stability, narrow size distribution as well as prominent photothermal conversion efficiency, and exhibited pronounced targeting and theranostics potential. A conjugate of transferrin, NIR dye Cy5.5 and cytotoxic chelating agent (NNE3TA:2,2'-(7-(2-((carboxymethyl)(4nitrobenzyl)amino)ethyl)-1,4,7-triazonane-1,4-diyl)diacetic acid) (NNE3TA-Transferrin-Cy5.5) was developed to treat and detect cancers (Kang et al., 2016). Targeted iron chelation cancer therapy and NIR imaging were demonstrated effectively in vitro with NNE3TA-Transferrin-Cy5.5. Most recently, a drug-induced transferrin self-assembly strategy is developed to fabricate tumor-targeted NPs for fluorescence and PA dual-modal imaging-guided PTT of glioma (Figure 4) (Zhu et al., 2017). In this system, transferrin could effectively load ICG via hydrophobic interaction and hydrogen bonding. Specifically, the preparation method is safe, simple and mild without the use of any toxic reagents. The obtained Transferrin-ICG NAs showed effective active tumortargeting, good biocompability, prominent dual-modal imaging as well as PTT efficacy, and could be adopted for theranostics of both subcutaneous and orthotopic brain tumors.

Notably, transferrin was employed not only as an delivery vehicle but also as a targeting agent in these works. It has been reported than transferrin-functionalized silica NPs lost targeting abilities completely in serum-rich media, due to shielding effects of the adsorbed proteins (Salvati et al., 2013). The bioavailability of the large transferrin determines the targeting functionality in complex biological media. It is a challenge to maintain the targeting efficiency of transferrin-based NPs in vivo.

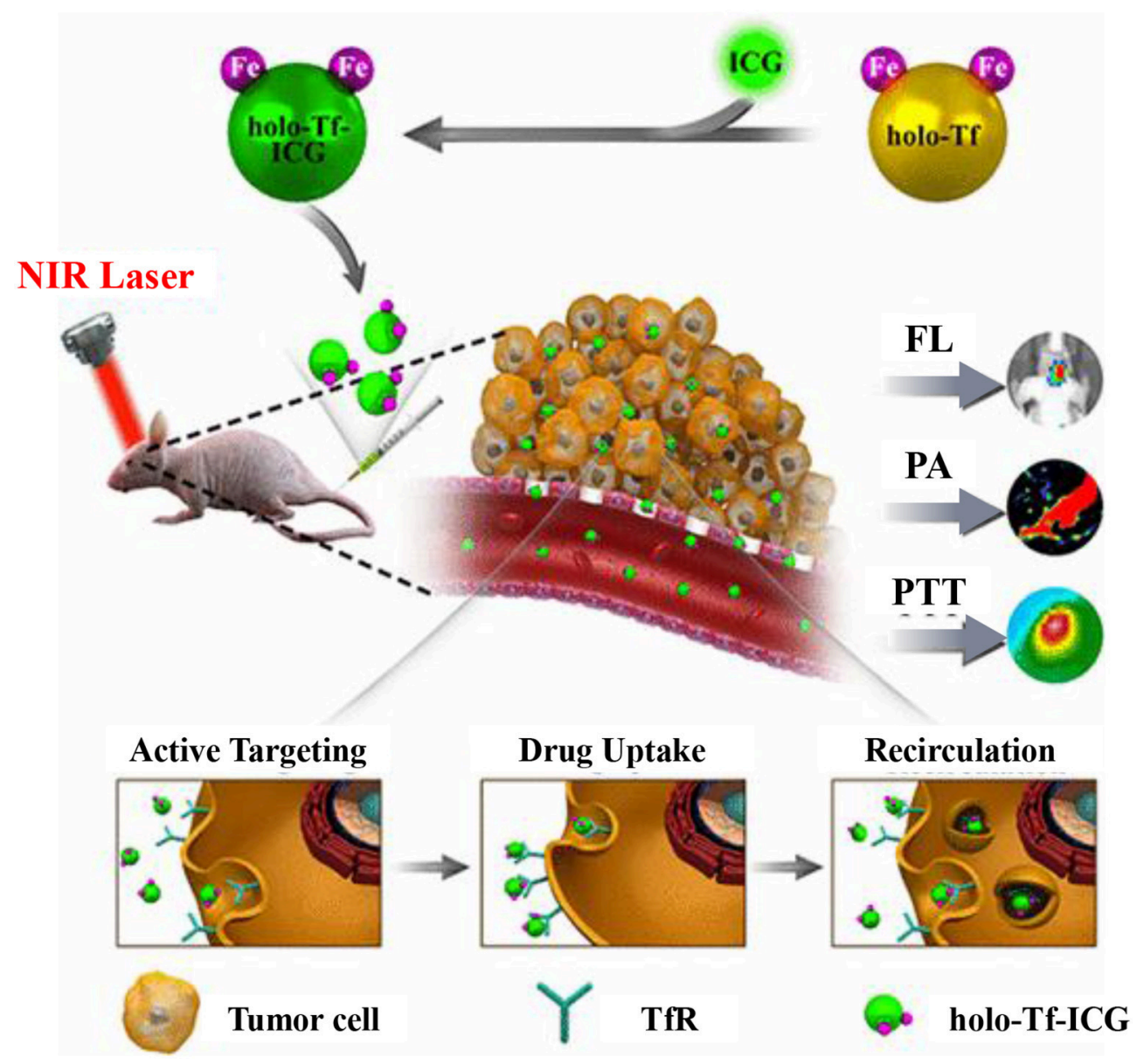

FIGURE 4 | Schematic illustration of holo-Transferrin-ICG complex for dual-modal imaging-guided cancer photothermal treatment in vivo. Reproduced with permission (Zhu et al., 2017). Copyright (2017) American Chemical Society. 


\section{OTHERS}

With the exception of the foregoing proteins, several other proteins, e.g., silk fibroin (Bian et al., 2016; Khalid et al., 2016; Liu et al., 2016), zein (Wang et al., 2017b), lipoprotein (Mathew et al., 2013; Alberti et al., 2015) and lactoferrin (Kamalapuram et al., 2016; Kanwar et al., 2016), have also been successfully employed for cancer theranostics, as detailed in Table 1. For instance, multimodular zinc-doped $\mathrm{Fe}_{3} \mathrm{O}_{4}$-saturated bovine lactoferrin NPs (Zn-Fe-bLf NPs) were fabricated for a targeted theranostics application through oral administration (Kamalapuram et al., 2016).

Although natural proteins were used in most studies, the disadvantages of these protein-based platforms were obvious, such as poor permeability, ease of degradation, and potential immune responses. Moreover, after functionalization or conjugation of other molecules, the protein properties and functions might be altered. In recent years, encapsulation of proteins by in situ polymerization was developed as an alternative strategies for protein modification (Ye et al., 2016b). The protein nanogels were obtained by incorporation of crosslinkers to protein surface and polymerization. Such protein nanogels can maintain the protein properties and functions in complex chemical or biological environment, and avoid the immunogenicity of proteins. The out layer polymers were cleavable and degradable, while the inner proteins could be released by internal and external stimuli. Numerous therapeutic proteins have been developed using this method for cancer therapy (Ye et al., 2016a, 2017).

\section{CONCLUSION AND PROSPECTS}

Natural proteins as biocompatible nanocarriers are broadly adopted in delivering therapeutic and diagnostic agents simultaneously. These nanoformulations are fabricated progressively complex and "smart" to employ multi functions in one platform. To increase the accuracy of diagnostic and

\section{REFERENCES}

Aisen, P., Leibman, A., and Zweier, J. (1978). Stoichiometric and site characteristics of the binding of iron to human transferrin. J. Biol. Chem. 253, 1930-1937.

Alberti, D., Protti, N., Toppino, A., Deagostino, A., Lanzardo, S., Bortolussi, S., et al. (2015). A theranostic approach based on the use of a dual boron/Gd agent to improve the efficacy of Boron Neutron Capture Therapy in the lung cancer treatment. Nanomedicine 11, 741-750. doi: 10.1016/j.nano.2014.12.004

Alkhateeb, A. A., and Connor, J. R. (2013). The significance of ferritin in cancer: anti-oxidation, inflammation and tumorigenesis. Biochim. Biophys. Acta 1836, 245-254. doi: 10.1016/j.bbcan.2013.07.002

An, F. F., and Zhang, X. H. (2017). Strategies for preparing albumin-based nanoparticles for multifunctional bioimaging and drug delivery. Theranostics 7, 3667-3689. doi: 10.7150/thno. 19365

Anand, U., and Mukherjee, S. (2013). Binding, unfolding and refolding dynamics of serum albumins. Biochim. Biophys. Acta 1830, 5394-5404. doi: 10.1016/j.bbagen.2013.05.017

Aoun, F., Kourie, H. R., Artigas, C., and Roumeguère, T. (2015). Next revolution in molecular theranostics: personalized medicine for urologic cancers. Future Oncol. 11, 2205-2219. doi: 10.2217/fon.15.104 the efficiency of cancer therapy, "all-in-one" nanoplatforms are designed with more than two imaging strategies and more than two therapeutic methods. Surface modification with targeted molecules and controlled drug release are employed to spatially control the localization of administered NPs. The improved efficiencies in tumor imaging and ablation are verified both in vitro and in vivo. Despite these huge advances, the translation of natural protein nanoplatforms from laboratory to clinical trials remains an enormous challenge. More efforts should be made to improve the NP reproducibility, colloidal stability in biological environments, and drug-loading efficiency. Furthermore, live and spleen accumulation is a big barrier in clinical translation of all types of NPs. Accordingly, more understanding of bio-nano interactions is required, while more data of pharmacokinetics should be collected and analyzed. Long-term toxicity of nanoformulation is not well evaluated. In addition to mouse model, more animal models, e.g., beagle dogs, monkeys and gorillas, should serve for assessing the long-term toxicity and therapeutic effect. Engineering complex particles with multiple functions are currently achieved by chemists. Accurate diagnose of early stage of tumor and precision drug delivery to tumor site should be more considerable in the future developing of protein-based cancer theranostics.

\section{AUTHOR CONTRIBUTIONS}

YG, HZ, and GS: designed this work of review; DM, MZ, and LW: performed the literature search of the databases; YG: wrote the manuscript; HZ and GS: revised the manuscript. All authors approved the paper for publication.

\section{ACKNOWLEDGMENTS}

This work was supported by the National Natural Science Foundation of China (91743107, 21405084), Natural Science Foundation of Nantong City in China (MS12015053).
Banyard, S. H., Stammers, D. K., and Harrison, P. M. (1978). Electron density map of apoferritin at 2.8-A resolution. Nature 271, 282-284. doi: 10.1038/271282a0

Bardhan, R., Lal, S., Joshi, A., and Halas, N. J. (2011). Theranostic nanoshells: from probe design to imaging and treatment of cancer. Acc. Chem. Res. 44, 936-946. doi: $10.1021 / \operatorname{ar} 200023 \mathrm{x}$

Barreto, J. A., O’Malley, W., Kubeil, M., Graham, B., Stephan, H., and Spiccia, L. (2011). Nanomaterials: applications in cancer imaging and therapy. Adv. Mater. Weinheim. 23, H18-H40. doi: 10.1002/adma.201100140

Battogtokh, G., and Ko, Y. T. (2016). Graphene oxide-incorporated pHresponsive folate-albumin-photosensitizer nanocomplex as image-guided dual therapeutics. J. Control. Release 234, 10-20. doi: 10.1016/j.jconrel.2016.05.007

Bellini, M., Mazzucchelli, S., Galbiati, E., Sommaruga, S., Fiandra, L., Truffi, M., et al. (2014). Protein nanocages for self-triggered nuclear delivery of DNAtargeted chemotherapeutics in Cancer Cells. J. Control. Release 196, 184-196. doi: 10.1016/j.jconrel.2014.10.002

Bhushan, B., Kumar, S. U., Matai, I., Sachdev, A., Dubey, P., and Gopinath, P. (2014). Ferritin nanocages: a novel platform for biomedical applications. J. Biomed. Nanotechnol. 10, 2950-2976. doi: 10.1166/jbn.2014.1980

Bian, X., Wu, P., Sha, H., Qian, H., Wang, Q., Cheng, L., et al. (2016). Anti-EGFRiRGD recombinant protein conjugated silk fibroin nanoparticles for enhanced 
tumor targeting and antitumor efficiency. Onco. Targets Ther. 9, 3153-3162. doi: 10.2147/OTT.S100678

Brandsma, M. E., Jevnikar, A. M., and Ma, S. (2011). Recombinant human transferrin: beyond iron binding and transport. Biotechnol. Adv. 29, 230-238. doi: 10.1016/j.biotechadv.2010.11.007

Calzolari, A., Oliviero, I., Deaglio, S., Mariani, G., Biffoni, M., Sposi, N. M., et al. (2007). Transferrin receptor 2 is frequently expressed in human cancer cell lines. Blood Cells Mol. Dis. 39, 82-91. doi: 10.1016/j.bcmd.2007.0 2.003

Charron, D. M., Chen, J., and Zheng, G. (2015). Theranostic lipid nanoparticles for cancer medicine. Cancer Treat. Res. 166, 103-127. doi: 10.1007/978-3-319-16555-4_5

Chen, L., Zhou, X., Nie, W., Feng, W., Zhang, Q., Wang, W., et al. (2017a). Marriage of albumin-gadolinium complexes and MoS2 nanoflakes as cancer theranostics for dual-modality magnetic resonance/photoacoustic imaging and photothermal therapy. ACS Appl. Mater. Interfaces 9, 17786-17798. doi: 10.1021 acsami.7b04488

Chen, M. L., He, Y. J., Chen, X. W., and Wang, J. H. (2013). Quantum-dotconjugated graphene as a probe for simultaneous cancer-targeted fluorescent imaging, tracking, and monitoring drug delivery. Bioconjug. Chem. 24, 387-397. doi: 10.1021/bc3004809

Chen, Q., Liang, C., Wang, C., and Liu, Z. (2015a). An imagable and photothermal "Abraxane-like" nanodrug for combination cancer therapy to treat subcutaneous and metastatic breast tumors. Adv. Mater. Weinheim. 27, 903-910. doi: 10.1002/adma.201404308

Chen, Q., Liang, C., Wang, X., He, J., Li, Y., and Liu, Z. (2014a). An albuminbased theranostic nano-agent for dual-modal imaging guided photothermal therapy to inhibit lymphatic metastasis of cancer post surgery. Biomaterials 35 , 9355-9362. doi: 10.1016/j.biomaterials.2014.07.062

Chen, Q., and Liu, Z. (2016). Albumin carriers for cancer theranostics: a conventional platform with new promise. Adv. Mater. Weinheim. 28, 10557-10566. doi: 10.1002/adma.201600038

Chen, Q., Wang, C., Cheng, L., He, W., Cheng, Z., and Liu, Z. (2014b). Protein modified upconversion nanoparticles for imaging-guided combined photothermal and photodynamic therapy. Biomaterials 35, 2915-2923. doi: 10.1016/j.biomaterials.2013.12.046

Chen, Q., Wang, C., Zhan, Z., He, W., Cheng, Z., Li, Y., et al. (2014c). Near-infrared dye bound albumin with separated imaging and therapy wavelength channels for imaging-guided photothermal therapy. Biomaterials 35, 8206-8214. doi: 10.1016/j.biomaterials.2014.06.013

Chen, Q., Wang, X., Wang, C., Feng, L., Li, Y., and Liu, Z. (2015b). Drug-induced self-assembly of modified albumins as nano-theranostics for tumor-targeted combination therapy. ACS Nano 9, 5223-5233. doi: 10.1021/acsnano.5b00640

Chen, Y., Wu, Y., Sun, B., Liu, S., and Liu, H. (2017b). Two-dimensional nanomaterials for cancer nanotheranostics. Small 13:1603446. doi: 10.1002/smll.201603446

Cheng, Z., Dai, Y., Kang, X., Li, C., Huang, S., Lian, H., et al. (2014). Gelatin-encapsulated iron oxide nanoparticles for platinum (IV) prodrug delivery, enzyme-stimulated release and MRI. Biomaterials 35, 6359-6368. doi: 10.1016/j.biomaterials.2014.04.029

Conti, L., Lanzardo, S., Ruiu, R., Cadenazzi, M., Cavallo, F., Aime, S., et al. (2016). L-Ferritin targets breast cancer stem cells and delivers therapeutic and imaging agents. Oncotarget 7, 66713-66727. doi: 10.18632/oncotarget.10920

Dai, Z., and Yue, X. (2017). Liposomal nanotechnology for cancer theranostics. Curr. Med. Chem. doi: 10.2174/0929867324666170306105350. [Epub ahead of print].

Dong, C., Liu, Z., Wang, S., Zheng, B., Guo, W., Yang, W., et al. (2016). A proteinpolymer bioconjugate-coated upconversion nanosystem for simultaneous tumor cell imaging, photodynamic therapy, and chemotherapy. ACS Appl. Mater. Interfaces 8, 32688-32698. doi: 10.1021/acsami.6b11803

Dufès, C., Al Robaian, M., and Somani, S. (2013). Transferrin and the transferrin receptor for the targeted delivery of therapeutic agents to the brain and cancer cells. Ther. Deliv. 4, 629-640. doi: 10.4155/tde.13.21

Elzoghby, A. O. (2013). Gelatin-based nanoparticles as drug and gene delivery systems: reviewing three decades of research. J. Control. Release 172, 1075-1091. doi: 10.1016/j.jconrel.2013.09.019

Foox, M., and Zilberman, M. (2015). Drug delivery from gelatin-based systems. Expert Opin. Drug Deliv. 12, 1547-1563. doi: 10.1517/17425247.2015.1037272
Fürst, W., and Banerjee, A. (2005). Release of glutaraldehyde from an albuminglutaraldehyde tissue adhesive causes significant in vitro and in vivo toxicity. Ann. Thorac. Surg. 79, 1522-1528. doi: 10.1016/j.athoracsur.2004.11.054

Gao, F. P., Lin, Y. X., Li, L. L., Liu, Y., Mayerhöffer, U., Spenst, P., et al. (2014). Supramolecular adducts of squaraine and protein for noninvasive tumor imaging and photothermal therapy in vivo. Biomaterials 35, 1004-1014. doi: 10.1016/j.biomaterials.2013.10.039

Ge, Z., and Liu, S. (2013). Functional block copolymer assemblies responsive to tumor and intracellular microenvironments for site-specific drug delivery and enhanced imaging performance. Chem. Soc. Rev. 42, 7289-7325. doi: $10.1039 / \mathrm{c} 3 \mathrm{cs} 60048 \mathrm{c}$

Gelperina, S., Kisich, K., Iseman, M. D., and Heifets, L. (2005). The potential advantages of nanoparticle drug delivery systems in chemotherapy of tuberculosis. Am. J. Respir. Crit. Care Med. 172, 1487-1490. doi: $10.1164 / \mathrm{rccm} .200504-613 \mathrm{PP}$

Geninatti Crich, S., Cadenazzi, M., Lanzardo, S., Conti, L., Ruiu, R., Alberti, D., et al. (2015). Targeting ferritin receptors for the selective delivery of imaging and therapeutic agents to breast cancer cells. Nanoscale 7, 6527-6533. doi: 10.1039/C5NR00352K

Gomme, P. T., McCann, K. B., and Bertolini, J. (2005). Transferrin: structure, function and potential therapeutic actions. Drug Discov. Today 10, 267-273. doi: 10.1016/S1359-6446(04)03333-1

Guo, J., Rahme, K., He, Y., Li, L. L., Holmes, J. D., and O’Driscoll, C. M. (2017). Gold nanoparticles enlighten the future of cancer theranostics. Int. J. Nanomed. 12, 6131-6152. doi: 10.2147/IJN.S140772

Han, H., Wang, J., Chen, T., Yin, L., Jin, Q., and Ji, J. (2017). Enzyme-sensitive gemcitabine conjugated albumin nanoparticles as a versatile theranostic nanoplatform for pancreatic cancer treatment. J. Colloid Interface Sci. 507, 217-224. doi: 10.1016/j.jcis.2017.07.047

Hanahan, D., and Weinberg, R. A. (2011). Hallmarks of cancer: the next generation. Cell 144, 646-674. doi: 10.1016/j.cell.2011.02.013

Hou, L., Shan, X., Hao, L., Feng, Q., and Zhang, Z. (2017). Copper sulfide nanoparticle-based localized drug delivery system as an effective cancer synergistic treatment and theranostic platform. Acta Biomater. 54, 307-320. doi: 10.1016/j.actbio.2017.03.005

Hu, D., Sheng, Z., Gao, G., Siu, F., Liu, C., Wan, Q., et al. (2016). Activatablet albumin-photosensitizer nanoassemblies for triple-modal imaging and thermal-modulated photodynamic therapy of cancer. Biomaterials 93, 10-19. doi: 10.1016/j.biomaterials.2016.03.037

Hu, G., Chun, X., Wang, Y., He, Q., and Gao, H. (2015). Peptide mediated active targeting and intelligent particle size reduction-mediated enhanced penetrating of fabricated nanoparticles for triple-negative breast cancer treatment. Oncotarget 6, 41258-41274. doi: 10.18632/oncotarget.5692

Huang, H. C., Barua, S., Sharma, G., Dey, S. K., and Rege, K. (2011). Inorganic nanoparticles for cancer imaging and therapy. J. Control. Release 155, 344-357. doi: 10.1016/j.jconrel.2011.06.004

Huang, H., Yang, D. P., Liu, M., Wang, X., Zhang, Z., Zhou, G., et al. (2017). pH-sensitive Au-BSA-DOX-FA nanocomposites for combined CT imaging and targeted drug delivery. Int. J. Nanomed. 12, 2829-2843. doi: $10.2147 / \mathrm{IJN} . S 128270$

Huang, P., Rong, P., Jin, A., Yan, X., Zhang, M. G., Lin, J., et al. (2014). Dyeloaded ferritin nanocages for multimodal imaging and photothermal therapy. Adv. Mater. Weinheim. 26, 6401-6408. doi: 10.1002/adma.201400914

Janib, S. M., Moses, A. S., and MacKay, J. A. (2010). Imaging and drug delivery using theranostic nanoparticles. Adv. Drug Deliv. Rev. 62, 1052-1063. doi: 10.1016/j.addr.2010.08.004

Jia, Q., Ge, J., Liu, W., Zheng, X., Wang, M., Zhang, H., et al. (2017). Biocompatible Iron Phthalocyanine-Albumin Assemblies as Photoacoustic and Thermal Theranostics in Living Mice. ACS Appl. Mater. Interf. 9, 21124-21132. doi: 10.1021/acsami.7b04360

Jiao, Y., Sun, Y., Tang, X., Ren, Q., and Yang, W. (2015). Tumortargeting multifunctional rattle-type theranostic nanoparticles for MRI/NIRF bimodal imaging and delivery of hydrophobic drugs. Small 11, 1962-1974. doi: 10.1002/smll.201402297

Kamalapuram, S. K., Kanwar, R. K., Roy, K., Chaudhary, R., Sehgal, R., and Kanwar, J. R. (2016). Theranostic multimodular potential of zinc-doped ferritesaturated metal-binding protein-loaded novel nanocapsules in cancers. Int. J. Nanomed. 11, 1349-1366. doi: 10.2147/IJN.S95253 
Kamaly, N., Xiao, Z., Valencia, P. M., Radovic-Moreno, A. F., and Farokhzad, O. C. (2012). Targeted polymeric therapeutic nanoparticles: design, development and clinical translation. Chem. Soc. Rev. 41, 2971-3010. doi: 10.1039/c2cs15344k

Kang, C. S., Ren, S., Sun, X., and Chong, H. S. (2016). Theranostic Polyaminocarboxylate-Cyanine-Transferrin Conjugate for Anticancer Therapy and Near-Infrared Optical Imaging. Chem. Med. Chem. 11, 2188-2193. doi: $10.1002 / \mathrm{cmdc} .201600072$

Kanwar, J. R., Kamalapuram, S. K., Krishnakumar, S., and Kanwar, R. K. (2016). Multimodal iron oxide (Fe3O4)-saturated lactoferrin nanocapsules as nanotheranostics for real-time imaging and breast cancer therapy of claudin-low, triple-negative (ER(-)/PR(-)/HER2(-)). Nanomedicine (Lond). 11, 249-268. doi: 10.2217/nnm.15.199

Karimi, M., Bahrami, S., Ravari, S. B., Zangabad, P. S., Mirshekari, H., Bozorgomid, M., et al. (2016). Albumin nanostructures as advanced drug delivery systems. Expert Opin. Drug Deliv. 13, 1609-1623. doi: 10.1080/17425247.2016.1193149

Khalid, A., Mitropoulos, A. N., Marelli, B., Tomljenovic-Hanic, S., and Omenetto, F. G. (2016). Doxorubicin loaded nanodiamond-silk spheres for fluorescence tracking and controlled drug release. Biomed. Opt. Express 7, 132-147. doi: 10.1364/BOE.7.000132

Kouchakzadeh, H., and Abbas Shojaosadati, S. (2016). The prominent role of protein-based delivery systems on the development of cancer treatment. Curr. Pharm. Des. 22, 3455-3465. doi: 10.2174/1381612822666160204120643

Lee, C., Lee, S., Thao, L. Q., Hwang, H. S., Kim, J. O., Lee, E. S., et al. (2016). An albumin nanocomplex-based endosomal $\mathrm{pH}$-activatable on/off probe system. Colloids Surf. B Biointerf. 144, 327-334. doi: 10.1016/j.colsurfb.2016.04.022

Li, F., Liang, Z., and Ling, D. (2017). Smart organic-inorganic nanogels for activatable theranostics. Curr. Med. Chem. doi: 10.2174/0929867324666170920164614. [Epub ahead of print].

Li, W. M., Chen, S. Y., and Liu, D. M. (2013). In situ doxorubicin$\mathrm{CaP}$ shell formation on amphiphilic gelatin-iron oxide core as a multifunctional drug delivery system with improved cytocompatibility, pH-responsive drug release and MR imaging. Acta Biomater. 9, 5360-5368. doi: 10.1016/j.actbio.2012.09.023

Li, X., Mu, J., Liu, F., Tan, E. W., Khezri, B., Webster, R. D., et al. (2015). Human transport protein carrier for controlled photoactivation of antitumor prodrug and real-time intracellular tumor imaging. Bioconjug. Chem. 26, 955-961. doi: 10.1021/acs.bioconjchem.5b00170

Lisitskiy, V. A., Khan, H., Popova, T. V., Chubarov, A. S., Zakharova, O. D., Akulov, A. E., et al. (2017). Multifunctional human serum albumintherapeutic nucleotide conjugate with redox and $\mathrm{pH}$-sensitive drug release mechanism for cancer theranostics. Bioorg. Med. Chem. Lett. 27, 3925-3930. doi: 10.1016/j.bmcl.2017.05.084

Liu, J., Qi, C., Tao, K., Zhang, J., Zhang, J., Xu, L., et al. (2016). Sericin/dextran injectable hydrogel as an optically trackable drug delivery system for malignant melanoma treatment. ACS Appl. Mater. Interfaces 8, 6411-6422. doi: 10.1021/acsami.6b00959

Liu, Y., Zhang, G., Guo, Q., Ma, L., Jia, Q., Liu, L., et al. (2017). Artificially controlled degradable inorganic nanomaterial for cancer theranostics. Biomaterials 112, 204-217. doi: 10.1016/j.biomaterials.2016.10.028

Maham, A., Tang, Z., Wu, H., Wang, J., and Lin, Y. (2009). Proteinbased nanomedicine platforms for drug delivery. Small 5, 1706-1721. doi: 10.1002/smll.200801602

Majorek, K. A., Porebski, P. J., Dayal, A., Zimmerman, M. D., Jablonska, K., Stewart, A. J., et al. (2012). Structural and immunologic characterization of bovine, horse, and rabbit serum albumins. Mol. Immunol. 52, 174-182. doi: 10.1016/j.molimm.2012.05.011

Mathew, S., Murakami, T., Nakatsuji, H., Okamoto, H., Morone, N., Heuser, J. E., et al. (2013). Exclusive photothermal heat generation by a gadolinium bis(naphthalocyanine) complex and inclusion into modified high-density lipoprotein nanocarriers for therapeutic applications. ACS Nano 7, 8908-8916. doi: $10.1021 / \mathrm{nn} 403384 \mathrm{k}$

Mehra, N. K., Jain, A. K., and Nahar, M. (2017). Carbon nanomaterials in oncology: an expanding horizon. Drug Discov. Today. doi: 10.1016/j.drudis.2017.09.013. [Epub ahead of print].

Mo, Y., Barnett, M. E., Takemoto, D., Davidson, H., and Kompella, U. B. (2007). Human serum albumin nanoparticles for efficient delivery of $\mathrm{Cu}, \mathrm{Zn}$ superoxide dismutase gene. Mol. Vis. 13, 746-757.
Mohammadi, M., Ramezani, M., Abnous, K., and Alibolandi, M. (2017). Biocompatible polymersomes-based cancer theranostics: Towards multifunctional nanomedicine. Int. J. Pharm. 519, 287-303. doi: 10.1016/j.ijpharm.2017.01.037

Moon, H., Kang, J., Sim, C., Kim, J., Lee, H., Chang, J. H., et al. (2015). Multifunctional theranostic contrast agent for photoacousticsand ultrasound-based tumor diagnosis and ultrasound-stimulated local tumor therapy. J. Control. Release 218, 63-71. doi: 10.1016/j.jconrel.2015.0 9.060

Muthu, M. S., Kutty, R. V., Luo, Z., Xie, J., and Feng, S. S. (2015). Theranostic vitamin E TPGS micelles of transferrin conjugation for targeted co-delivery of docetaxel and ultra bright gold nanoclusters. Biomaterials 39, 234-248. doi: 10.1016/j.biomaterials.2014.11.008

Nezhadi, S. H., Choong, P. F., Lotfipour, F., and Dass, C. R. (2009). Gelatinbased delivery systems for cancer gene therapy. J. Drug Target. 17, 731-738. doi: 10.3109/10611860903096540

Ng, K. K., Lovell, J. F., and Zheng, G. (2011). Lipoprotein-inspired nanoparticles for cancer theranostics. Acc. Chem. Res. 44, 1105-1113. doi: 10.1021/ar200017e

Ninan, G., Jose, J., and Abubacker, Z. (2011). Preparation and characterization of gelatin extracted from the skins of rohu (labeo rohita) and common carp (cyprinus carpio). J. Food Process. Pres. 35, 143-162. doi: 10.1111/j.1745-4549.2009.00467.x

Opoku-Damoah, Y., Wang, R., Zhou, J., and Ding, Y. (2016). Versatile nanosystem-based cancer theranostics: design inspiration and predetermined routing. Theranostics 6, 986-1003. doi: 10.7150/thno.14860

Paliwal, R., and Palakurthi, S. (2014). Zein in controlled drug delivery and tissue engineering. J. Control. Release 189, 108-122. doi: 10.1016/j.jconrel.2014.06.036

Pan, J., Wang, Y., Pan, H., Zhang, C., Zhang, X., Fu, Y.-Y., et al. (2017). Mimicking drug-substrate interaction: a smart bioinspired technology for the fabrication of theranostic nanoprobes. Adv. Funct. Mater. 27:1603440. doi: 10.1002/adfm.201603440

Panyam, J., and Labhasetwar, V. (2003). Biodegradable nanoparticles for drug and gene delivery to cells and tissue. Adv. Drug Deliv. Rev. 55, 329-347. doi: 10.1016/S0169-409X(02)00228-4

Parkkinen, J., von Bonsdorff, L., Ebeling, F., and Sahlstedt, L. (2002). Function and therapeutic development of apotransferrin. Vox Sang 83 (Suppl. 1), 321-326. doi: 10.1111/j.1423-0410.2002.tb05327.x

Patel, Z. S., Yamamoto, M., Ueda, H., Tabata, Y., and Mikos, A. G. (2008) Biodegradable gelatin microparticles as delivery systems for the controlled release of bone morphogenetic protein-2. Acta Biomater. 4, 1126-1138. doi: 10.1016/j.actbio.2008.04.002

Peer, D., Karp, J. M., Hong, S., Farokhzad, O. C., Margalit, R., and Langer, R. (2007). Nanocarriers as an emerging platform for cancer therapy. Nat. Nanotechnol. 2, 751-760. doi: 10.1038/nnano.2007.387

Pene, F., Courtine, E., Cariou, A., and Mira, J. P. (2009). Toward theragnostics. Crit. Care Med. 37, S50-S58. doi: 10.1097/CCM.0b013e3181921349

Peng, H., Tang, J., Zheng, R., Guo, G., Dong, A., Wang, Y., et al. (2017). Nucleartargeted multifunctional magnetic nanoparticles for photothermal therapy. Adv. Healthc. Mater. 6:1601289. doi: 10.1002/adhm.201601289

Pérez-Tomás, R. (2006). Multidrug resistance: retrospect and prospects in anti-cancer drug treatment. Curr. Med. Chem. 13, 1859-1876. doi: 10.2174/092986706777585077

Rong, P., Huang, P., Liu, Z., Lin, J., Jin, A., Ma, Y., et al. (2015). Protein-based photothermal theranostics for imaging-guided cancer therapy. Nanoscale 7, 16330-16336. doi: 10.1039/C5NR04428F

Sahoo, N., Sahoo, R. K., Biswas, N., Guha, A., and Kuotsu, K. (2015). Recent advancement of gelatin nanoparticles in drug and vaccine delivery. Int. J. Biol. Macromol. 81, 317-331. doi: 10.1016/j.ijbiomac.2015.08.006

Sahu, A., Lee, J. H., Lee, H. G., Jeong, Y. Y., and Tae, G. (2016). Prussian blue/serum albumin/indocyanine green as a multifunctional nanotheranostic agent for bimodal imaging guided laser mediated combinatorial phototherapy. J. Control. Release 236, 90-99. doi: 10.1016/j.jconrel.2016.0 6.031

Salvati, A., Pitek, A. S., Monopoli, M. P., Prapainop, K., Bombelli, F. B., Hristov, D. R., et al. (2013). Transferrin-functionalized nanoparticles lose their targeting capabilities when a biomolecule corona adsorbs on the surface. Nat. Nanotechnol. 8, 137-143. doi: 10.1038/nnano.2012.237 
Semkina, A., Abakumov, M., Grinenko, N., Abakumov, A., Skorikov, A., Mironova, E., et al. (2015). Core-shell-corona doxorubicin-loaded superparamagnetic Fe3O4 nanoparticles for cancer theranostics. Colloids Surf. B Biointerfaces 136, 1073-1080. doi: 10.1016/j.colsurfb.2015.11.009

Sharma, H., Mishra, P. K., Talegaonkar, S., and Vaidya, B. (2015). Metal nanoparticles: a theranostic nanotool against cancer. Drug Discov. Today 20, 1143-1151. doi: 10.1016/j.drudis.2015.05.009

Sheng, Z., Hu, D., Zheng, M., Zhao, P., Liu, H., Gao, D., et al. (2014). Smart human serum albumin-indocyanine green nanoparticles generated by programmed assembly for dual-modal imaging-guided cancer synergistic phototherapy. ACS Nano 8, 12310-12322. doi: 10.1021/nn5062386

Sheng, Z., Song, L., Zheng, J., Hu, D., He, M., Zheng, M., et al. (2013). Proteinassisted fabrication of nano-reduced graphene oxide for combined in vivo photoacoustic imaging and photothermal therapy. Biomaterials 34, 5236-5243. doi: 10.1016/j.biomaterials.2013.03.090

Sim, C., Kim, H., Moon, H., Lee, H., Chang, J. H., and Kim, H. (2015). Photoacoustic-based nanomedicine for cancer diagnosis and therapy. J. Control. Release 203, 118-125. doi: 10.1016/j.jconrel.2015.02.020

Sinha, V. R., and Trehan, A. (2003). Biodegradable microspheres for protein delivery. J. Control. Release 90, 261-280. doi: 10.1016/S0168-3659(03)00194-9

Sk, U. H., and Kojima, C. (2015). Dendrimers for theranostic applications. Biomol. Concepts 6, 205-217. doi: 10.1515/bmc-2015-0012

Sonali Singh, R. P., Singh, N., Sharma, G., Vijayakumar, M. R., Koch, B., and Muthu, M. S. (2016). Transferrin liposomes of docetaxel for brain-targeted cancer applications: formulation and brain theranostics. Drug Deliv. 23, 1261-1271. doi: 10.3109/10717544.2016.1162878

Suarasan, S., Focsan, M., Potara, M., Soritau, O., Florea, A., Maniu, D., et al. (2016). Doxorubicin-incorporated nanotherapeutic delivery system based on gelatin-coated gold nanoparticles: formulation, drug release, and multimodal imaging of cellular internalization. ACS Appl. Mater. Interfaces 8, 22900-22913. doi: 10.1021/acsami.6b07583

Sugio, S., Kashima, A., Mochizuki, S., Noda, M., and Kobayashi, K. (1999). Crystal structure of human serum albumin at 2.5 A resolution. Protein Eng. 12, 439-446. doi: 10.1093/protein/12.6.439

Szakács, G., Paterson, J. K., Ludwig, J. A., Booth-Genthe, C., and Gottesman, M. M. (2006). Targeting multidrug resistance in cancer. Nat. Rev. Drug Discov. 5, 219-234. doi: $10.1038 /$ nrd 1984

Szoke, D., and Panteghini, M. (2012). Diagnostic value of transferrin. Clin. Chim. Acta 413, 1184-1189. doi: 10.1016/j.cca.2012.04.021

Tekade, R. K., and Sun, X. (2017). The Warburg effect and glucosederived cancer theranostics. Drug Discov. Today 22, 1637-1653. doi: 10.1016/j.drudis.2017.08.003

Torre, L. A., Bray, F., Siegel, R. L., Ferlay, J., Lortet-Tieulent, J., and Jemal, A. (2015). Global cancer statistics, 2012. CA Cancer J. Clin. 65, 87-108. doi: $10.3322 /$ caac. 21262

Tortorella, S., and Karagiannis, T. C. (2014). Transferrin receptor-mediated endocytosis: a useful target for cancer therapy. J. Membr. Biol. 247, 291-307. doi: 10.1007/s00232-014-9637-0

Tran, T. T., Tran, P. H., Amin, H. H., and Lee, B. J. (2017a). Biodistribution and in vivo performance of fattigation-platform theranostic nanoparticles. Mater. Sci. Eng. C Mater. Biol. Appl. 79, 671-678. doi: 10.1016/j.msec.2017.05.029

Tran, T. T., Tran, P. H., Yoon, T. J., and Lee, B. J. (2017b). Fattigation-platform theranostic nanoparticles for cancer therapy. Mater. Sci. Eng. C Mater. Biol. Appl. 75, 1161-1167. doi: 10.1016/j.msec.2017.03.012

Tros de Ilarduya, C., and Düzgüneş, N. (2013). Delivery of therapeutic nucleic acids via transferrin and transferrin receptors: lipoplexes and other carriers. Expert Opin. Drug Deliv. 10, 1583-1591. doi: 10.1517/17425247.2013.837447

Truffi, M., Fiandra, L., Sorrentino, L., Monieri, M., Corsi, F., and Mazzucchelli, S. (2016). Ferritin nanocages: a biological platform for drug delivery, imaging and theranostics in cancer. Pharmacol. Res. 107, 57-65. doi: 10.1016/j.phrs.2016.03.002

Tsai, L. C., Hsieh, H. Y., Lu, K. Y., Wang, S. Y., and Mi, F. L. (2016). EGCG/gelatindoxorubicin gold nanoparticles enhance therapeutic efficacy of doxorubicin for prostate cancer treatment. Nanomedicine 11, 9-30. doi: 10.2217/nnm.15.183

Turino, L. N., Ruggiero, M. R., Stefanìa, R., Cutrin, J. C., Aime, S., and Geninatti Crich, S. (2017). Ferritin decorated PLGA/paclitaxel loaded nanoparticles endowed with an enhanced toxicity toward MCF-7 breast tumor cells. Bioconjug. Chem. 28, 1283-1290. doi: 10.1021/acs.bioconjchem.7b00096
Wang, D., Li, Y., Tian, Z., Cao, R., and Yang, B. (2014a). Transferrinconjugated nanodiamond as an intracellular transporter of chemotherapeutic drug and targeting therapy for cancer cells. Ther. Deliv. 5, 511-524. doi: $10.4155 /$ tde. 14.17

Wang, D., Zhu, L., Pu, Y., Wang, J. X., Chen, J. F., and Dai, L. (2017a). Transferrin-coated magnetic upconversion nanoparticles for efficient photodynamic therapy with near-infrared irradiation and luminescence bioimaging. Nanoscale 9, 11214-11221. doi: 10.1039/C7NR03019C

Wang, F., Chen, L., Zhang, R., Chen, Z., and Zhu, L. (2014b). RGD peptide conjugated liposomal drug delivery system for enhance therapeutic efficacy in treating bone metastasis from prostate cancer. J. Control. Release 196, 222-233. doi: 10.1016/j.jconrel.2014.1 0.012

Wang, H., Zhu, W., Huang, Y., Li, Z., Jiang, Y., and Xie, Q. (2017b). Facile encapsulation of hydroxycamptothecin nanocrystals into zein-based nanocomplexes for active targeting in drug delivery and cell imaging. Acta Biomater. 61, 88-100. doi: 10.1016/j.actbio.2017.04.017

Wang, K., Zhang, Y., Wang, J., Yuan, A., Sun, M., Wu, J., et al. (2016a). Selfassembled IR780-loaded transferrin nanoparticles as an imaging, targeting and PDT/PTT agent for cancer therapy. Sci. Rep. 6:27421. doi: 10.1038/srep27421

Wang, L., An, Y., Yuan, C., Zhang, H., Liang, C., Ding, F., et al. (2015). GEM-loaded magnetic albumin nanospheres modified with cetuximab for simultaneous targeting, magnetic resonance imaging, and double-targeted thermochemotherapy of pancreatic cancer cells. Int. J. Nanomed. 10, 2507-2519. doi: 10.2147/IJN.S77642

Wang, Z., Huang, P., Jacobson, O., Wang, Z., Liu, Y., Lin, L., et al. (2016b). Biomineralization-inspired synthesis of copper sulfide-ferritin nanocages as cancer theranostics. ACS Nano 10, 3453-3460. doi: 10.1021/acsnano.5b07521

Wei, K. C., Lin, F. W., Huang, C. Y., Ma, C. C., Chen, J. Y., Feng, L. Y., et al. (2016). 1,3-Bis(2-chloroethyl)-1-nitrosourea-loaded bovine serum albumin nanoparticles with dual magnetic resonance-fluorescence imaging for tracking of chemotherapeutic agents. Int. J. Nanomed. 11, 4065-4075. doi: $10.2147 /$ IJN.S113589

Wen, L., Yang, S., Zhong, J., Zhou, Q., and Xing, D. (2017). Thermoacoustic imaging and therapy guidance based on ultra-short pulsed microwave pumped thermoelastic effect induced with superparamagnetic iron oxide nanoparticles. Theranostics 7, 1976-1989. doi: 10.7150/thno.17846

Yang, W., Guo, W., Le, W., Lv, G., Zhang, F., Shi, L., et al. (2016). Albuminbioinspired Gd:CuS nanotheranostic agent for in vivo photoacoustic/magnetic resonance imaging-guided tumor-targeted photothermal therapy. ACS Nano 10, 10245-10257. doi: 10.1021/acsnano.6b05760

Ye, Y. Q., Yu, J. C., and Gu, Z. (2016b). Versatile protein nanogels prepared by in situ polymerization. Macromol. Chem. Phys. 217, 333-343. doi: 10.1002/macp.201500296

Ye, Y., Wang, C., Zheng, X., Hu, Q., Zhang, Y., Liu, Q., et al. (2017). A melanin-mediated cancer immunotherapy patch. Sci. Immunol. 2:eaan5692. doi: 10.1126/sciimmunol.aan5692

Ye, Y., Wang, J., Hu, Q., Hochu, G. M., Xin, H., Wang, C., et al. (2016a). Synergistic transcutaneous immunotherapy enhances antitumor immune responses through delivery of checkpoint inhibitors. ACS Nano 10, 8956-8963. doi: 10.1021/acsnano.6b04989

Yewale, C., Baradia, D., Vhora, I., and Misra, A. (2013). Proteins: emerging carrier for delivery of cancer therapeutics. Expert Opin. Drug Deliv. 10, 1429-1448. doi: 10.1517/17425247.2013.805200

Yu, J., Ju, Y., Zhao, L., Chu, X., Yang, W., Tian, Y., et al. (2016). Multistimuliregulated photochemothermal cancer therapy remotely controlled via Fe5C2 nanoparticles. ACS Nano 10, 159-169. doi: 10.1021/acsnano.5b 04706

Yue, X., Zhang, Q., and Dai, Z. (2017). Near-infrared light-activatable polymeric nanoformulations for combined therapy and imaging of cancer. Adv. Drug Deliv. Rev. 115, 155-170. doi: 10.1016/j.addr.2017.04.007

Zhen, Z., Tang, W., Chen, H., Lin, X., Todd, T., Wang, G., et al. (2013a). RGDmodified apoferritin nanoparticles for efficient drug delivery to tumors. ACS Nano 7, 4830-4837. doi: 10.1021/nn305791q

Zhen, Z., Tang, W., Guo, C., Chen, H., Lin, X., Liu, G., et al. (2013b). Ferritin nanocages to encapsulate and deliver photosensitizers for efficient photodynamic therapy against cancer. ACS Nano 7, 6988-6996. doi: $10.1021 / \mathrm{nn} 402199 \mathrm{~g}$ 
Zhou, L., Yang, T., Wang, J., Wang, Q., Lv, X., Ke, H., et al. (2017). SizeTunable Gd2O3@albumin nanoparticles conjugating chlorin e6 for magnetic resonance imaging-guided photo-induced therapy. Theranostics 7, 764-774. doi: 10.7150/thno.15757

Zhu, H., Zhang, S., Ling, Y., Meng, G., Yang, Y., and Zhang, W. (2015). pHresponsive hybrid quantum dots for targeting hypoxic tumor siRNA delivery. $J$. Control. Release 220, 529-544. doi: 10.1016/j.jconrel.2015.11.017

Zhu, M., Sheng, Z., Jia, Y., Hu, D., Liu, X., Xia, X., et al. (2017). Indocyanine Greenholo-Transferrin Nanoassemblies for Tumor-Targeted Dual-Modal Imaging and Photothermal Therapy of Glioma. ACS Appl. Mater. Interf. 9, 39249-39258. doi: 10.1021/acsami.7b14076
Conflict of Interest Statement: The authors declare that the research was conducted in the absence of any commercial or financial relationships that could be construed as a potential conflict of interest.

Copyright (c) 2018 Gou, Miao, Zhou, Wang, Zhou and Su. This is an open-access article distributed under the terms of the Creative Commons Attribution License (CC BY). The use, distribution or reproduction in other forums is permitted, provided the original author(s) and the copyright owner are credited and that the original publication in this journal is cited, in accordance with accepted academic practice. No use, distribution or reproduction is permitted which does not comply with these terms. 